\title{
Estudio teológico-pastoral de la "Instrucción sobre algunos aspectos de la teología de la liberación"
}

\section{IGNACIO ELLACURIA}

\author{
Centro de Reflexión Teológica, San Salvador
}

El 6 de agosto de 1984 la Sagrada Congregación para la Doctrina de la Fe fechaba una 'instrucción' que por su contenido y por su forma constituye un paso importante en el debate sobre la teologia de la liberación.' Aunque en el mismo documento se anuncia uno ulterior "que pondrá en evidencia, de modo positivo" todas las riquezas doctrinales y prácticas del vasto tema de la libertad cristiana y de la liberación (Introducción), puede pensarse que se ha alcanzado ya el máximo nivel de critica frente al fenómeno de la teología de la liberación, tal como ésta se ha venido dando históricamente en América Latina hace ya más de quince años. La campaña contra ella que desde el lado económico-político fue emprendida por Rockefeller, el grupo de Santa Fe y tantas otras fuerzas conservadoras y represoras en América Latina y que desde el lado eclesiástico fue conducida sobre todo por Veckemans, López Trujillo y Kloppenburg, cambió de rumbo cuando fue objeto de estudio por la Comisión Teológica Internacional en $1976 .{ }^{2}$ La Evangelii Nuntiandi (1976) el sinodo de los obispos en dos ocasiones (1971 y 1974), y, especialmente, Medellin (1968) y Puebla (1979), así como diversas intervenciones de Juan Pablo II, han recogido con mayor cuidado el tema. Mientras tanto, distintos teólogos de la liberación han sido convocados a Roma para que de palabra o por escrito den ulteriores explicaciones o precisiones de algunas de sus arientaciones o afirmaciones. Asimismo algunas conferencias episcopales han sido urgidas a tomar posición sobre algún teólogo en particular como ha sido el caso de la peruana respecto de Gustavo Gutiérrez uno de los más connotados y representativos teólogos de la liberación. Finalmente, pocas fechas antes de que apareciera la Instrucción, una revista italiana de conocida trayectoria político-eclesiástica se hacia con el texto que Ratzinger habia expuesto en altas esferas vaticanas y que concluia apelando a la necesidad de hacer algo contra lo que se estimaba como peligroso para la fe y para la Iglesia. ${ }^{3}$

Por los antecedentes del documento y por el apoyo que su publicacion recibe del propio Juan Pablo Il, pensamos que, independientemente de su valor magisterial estrictamente entendido, debe tenérsele muy en cuenta desde una 
perspectiva pastoral. Efectivamente, aunque se trata sólo de una 'instrucción, punto sobre el cual volveremos inmediatamente no puede desconocerse la aprobación que ha recibido del Papa y de la cual se hace especial referencia en el texto, cosa no inusual, pero sí significativa: "El Santo Padre Juan Pablo Il, en el transcurso de una Audiencia concedida al infrascrito Prefecto, ha aprobado esta Instrucción, cuya preparación fue decidida en una reunión ordinaria de la Congregación para la Doctrina de la Fe, y ha ordenado su publicación" " (Conclusión).

El documento en cuestión emana efectivamente de la Santa Sede. Aunque el nuevo Derecho Canónico sólo dedica dos cánones, el 360 y 361, a la aclaración jurídica de esa estructura compleja que es la curia romana, si advierte que las congregaciones son parte de ella y que el romano pontifice suele tramitar los asuntos de la Iglesia universal a través de la curia, "que realiza su función en nombre y por autoridad del mismo para el bien y servicio de las Iglesias." 4 Pero como los distintos componentes del organismo pontificio realizan su función comprometiendo más o menos la autoridad magisterial y disciplinar del Papa, sería importante determinar formalmente el valor magisterial que se debe atribuir a una 'instrucción.' Sobre este punto el nuevo Derecho Canónico nos deja a oscuras, por cuanto lo que en èl se entiende por ese término no se aplica al documento que estamos comentando, sino de un modo muy lejano. Y si se aplicara tendria un sentido más disciplinar que magisterial. ${ }^{5}$ Se tràta, en efecto, de un concepto nuevo en el código, aunque ya lo venian utilizando las congregaciones romanas, pero tal como ha sido recogido tiene un carácter ejecutivo y no doctrinal. ${ }^{6}$

La propia Instrucción insiste en las limitaciones de la misma: “La presente Instrucción tiene un fin más preciso y limitado: atraer la atención de los pastores, de los teblogos y de todos los fieles, sobre las desviaciones y riesgos de desviación, ruinosos para la fe y para la vida cristiana, que implican ciertas formas de teología de la liberación que recurren, de modo insuficientemente critico, a conceptos tomados de diversas corrientes del pensamiento marxista" (Introducción). La primera limitación es la de su objeto: sólo se refiere a determinadas teologias de la liberación y no a todas; se refiere a las que recurren a conceptos tomados de diversas corrientes del pensamiento marxista, pero no a todas ellas, sino a las que lo hacen de modo insuficientemente crítico. La segunda limitación es la de su proposito: no se trata de una condena, sino más bien de un intento por atraer la atención sobre desviaciones en unos casos y sólo riesgos de desviacion en otros. La terceta limitación es que no se atreve a sefialar autores y obras que realmente sostengan esas desviaciones y riesgos de desviacion.

Monseñor Quarracino, presidente del CELAM, en la presentación que hizo de la Instrucción en Roma insistía en que se trata de una "llamada de atencion, $" 17$ incluso de una fuerte llamada de atención hecha por el organo competente en cuestiones de doctrina para lo cual tiene derecho y deber. Sobre la no cita explícita de autores y de textos dice que "es obvio que ha sido redactada teniendo en cuenta unos y otros." "Más aún el "Resumen del documento" que se repartio junto con él dice "no contiene ninguna cita directa sacada de obras 
importantes sobre la materia. Hacerlo seria dar a algunos, no explícitamente citados, el pretexto de decir que a ellos no les afecta el documento,' ción que desde una perspectiva jurídico-penal no deja de ser desconcertante, aunque desde un punto de vista pastoral pueda ser caritativa.

Es dificil, en consecuencia, ponderar el valor magisterial de este documento. Por un lado, es evidente que por la gravedad del problema tratado, por la preocupación que se advierte en todo su texto, por la importancia que se ha dado a su difusión, se trata de una intervención de la Santa Sede que no puede tomarse a la ligera o disvirtuarla con consideraciones de tipo político más o menos oportunista; se trata de un acto de magisterio ordinario con un perfil dogmático bajo que quiere adelantarse para que no se agrave el mal mientras se preparan pasos ulteriores doctrinales de mayor alcance. Por otro lado, sería arriesgado dar a este documento un valor dogmático excesivo en aquellas partes que no son propia y formalmente objeto de fe en cuanto al contenido. Hay en él demasiadas cosas mezcladas, cuya relación con la fe es muy distinta según los casos. Por ello, una correcta hermenéutica del documento exige diferenciar niveles, tanto desde el punto de vista de lo que está en relación con la fe, la moral y la pastoral, como desde el punto de vista de las distintas teologias de la liberación, respecto de las cuales hay que probar que sostienen objetivamente, como parte principal de ellas, concepciones inconciliables con la fe. El respeto al magisterio de la Iglesia pide ser muy cuidadoso precisamente para que ese magisterio no quede desautorizado con las evoluciones ulteriores del conocimiento científico, como ha ocurrido tantas veces. El documento tiene, sin duda, muchos valores los cuales deben ser recogidos tanto en lo que afirma como en lo que previene. Pero por lo mismo y para que esos valores cobren toda su eficacia, es menester distinguirlos de otras afirmaciones cuya vulnerabilidad es mayor.

A esto invita el propio presidente del CELAM en la presentación oficial del documento en Roma cuando dice: "es necesario añadir todavía que la Instrucción, como por lo demás todo documento de esta indole, contiene, por su propia naturaleza, una convocación a su estudio y profundización y debiera provocar a un diálogo profundo y sereno entre teólogos, en el interior de la Iglesia." 10 Si atendemos a los subrayados, los cuales no están en el texto original, tendremos pistas excelente para acercarnos a la Instruccion. Se trata, en efecto, de un documento de tal índole que por su naturaleza provoca el diálogo dentro de la Iglesia. Si es asi, no se trata de una imposición dogmática, la cual por su propia naturaleza, exige la aceptación y la profundización, pero no propiamente un diálogo profundo y sereno, con lo que éste supone de intercambio crítico y respetuoso de opiniones divergentes. Se trataría, por tanto, de una manifestación de la Santa Sede que, con ser muy importante y muy a tener en cuenta, es en sí misma algo incocluso y que debe continuarse cuidando de no ir demasiado adelante, pero también de no quedarse demasiado atrás.

Esta convicción nos ha llevado a hacer un estudio teológico-pastoral de la Instrucción, por entender que efectivamente ese es el carácter formal del documento. No seria lo más oportuno ni lo que más se acomodara a la indole del documento hacer un estudio teologico-crítico. Desde una perspectiva 
teológico-critica el documento en cuestión mostraria debilidades, tanto formales como de contenido, tanto de información como de interpretación, que obligarían a otras tomas de posición. Creemos que es más positivo enfocarlo desde una perspectiva teológico-pastoral para sacar de la Instrucción los mayores bienes posibles. Hay en la instrucción una preocupación preponderantemente pastoral más que propiamente técnico-teológica y se seria injusto con ella, si no se atendiera a este su propósito fundamental. Tomando en cuenta su carácter positivo, su intento de enfocar positivamente el problema, el análisis debe pretender lo mismo; cómo sacar el mayor provecho pastoral para las mayorias populares, sujeto primario de la liberación, de las advertencias que sobre la teología de la liberación, sobre algunos aspecios de ella, se hacen en el documento.

\section{Necesidad de una teología de la liberaclón}

Hasta ahora no se había insistido suficientemente desde Roma y de modo oficial en cuán necesaria y urgente es una teología de la liberación. El articulo de Ratzinger publicado en 30 Giornit habia insistido en la importancia capital que tenia para toda la Iglesia el nuevo movimiento teológico surgido en los últimos quince años a lo largo y ancho de toda la América Latina. En él se trata no de añadir un nuevo tratado teológico a los otros ya existentes, sino de una nueva hermenéutica de la fe cristiana, de una nueva forma de comprender y realizar el cristianismo en su totalidad; afecta, por tanto, a la teología en su estructura fundamental y no sólo en sus contenidos particulares y por eso mismo altera todas las formas de la vida eclesial. ${ }^{12}$ La teología de la liberación pretende dar una nueva interpretación global de lo cristiano al explicar el cristianismo como una praxis de liberación y constituirse ella misma en una introducción a esta praxis. Al propio Ratzinger le parece dificil negar que el conjunto de la teología de la liberación contiene una lógica casi irresistible y que con ella se ha logrado una visión de síntesis de lo cristiano, que parece responder plenamente, tanto a las exigencias de la ciencia como a los desafios morales de nuestro tiempo. ${ }^{13}$ Todo esto le parece peligrosisimo precisamente porque ha sido llevado a cabo, según él, por las teologías de la liberación más afectadas por el marxismo y que contienen mayores peligros para la fe y para la Iglesia.

Al parecer ha sido esta pujante empresa de los teólogos latinoamericanos la que ha puesto sobre los despachos noratlánticos el desafío de por qué en ellos -en sus aulas, en sus libros, en sus púlpitos- no se habia caido en la cuenta de la enorme importancia que para la fe y para la práctica cristiana tenian los temas específicos y el modo especifico de enfocar todos los otros temas que son propios de la teología de la liberación. En el magisterio eclesiástico romano la temática de la liberación - una parte de ella tan sólo- era recogida en lo que se denomina enseñanza o doctrina social de la Iglesia, esto es, como algo que muy indirectamente se tomaba como reo-logía. Desde la Rerum novarum hasta la Populorum progressio el problema de la injusticia y de sus soluciones han sido objeto de atención por parte de los papas. El Concilio Vaticano II, por su parte, en la Gaudium et Spes tomaba con gran aliento los problemas que afectaban al mundo de los hombres y los enfocaba teológica- 
mente, pero aun en ese caso se hacia desde la perspectiva de una constitución 'pastoral.' Sólo desde la Evangelii nuntiandi de Pablo VI y ya por claro influjo de la tcologia de la liberación, empezó a tomar relieve estrictamente teologico el nuevo horizonte y la nueva perspectiva. Las enciclicas sociales de Juan Pablo II siguen de nuevo la linea clásica de las de sus antecesores y es, sobre todo, en los discursos dirigidos al episcopado y/o a los fieles latinoamericanos donde se hace presente una perspectiva más estrictamente teológica sobre la liberación, esecialmente en el discurso inaugural de Puebla donde apuntó la necesidad de "alentar los compromisos pasiorales en este campo (de los derechos humanos) con una recta concepción cristiana de la liberación," 14 pero aun en este caso se situaba enseguida en la linea de la doctrina social de la Iglesia y no en la línea de una reo-logía estrictamente tal.

Esta misma ausencia hay que notarla en los trabajos teologicos europeos. Ninguno de los clásicos diccionarios teológicos calólicos, tales como Lexicon für Theologie und Kirche, Handbuch der theologischen Grundbegriffe, Sacramentum mundi, elc., hacen mención del concepto de liberacion, aunque si ampliamente del concepto de libertad. Asimismo un tema tan fundamental no se hace de ningún modo presente en el libro de Ratzinger Einführung in das Christentum. 15 En cambio, ya se le da bastante relieve como concepto fundamental en el Nuevo diccionario de teologia, dirigido por G. Barbaglio y S. Dianich y publicado en Roma en 1977. La liberación empieza a ser no una preocupación social de pastoralistas latinoamericanos - así fue considerada por muchos años en el mejor de los casos - sino un tópico de interés para la teologia, aunque todavia se estaba lejos de considerar que podia constituirse en una forma radicalmente nueva de hacer teologia.

Es digno de preguntarse como ha sido posible que un tema y un enfoque de tanta trancendencia teológica hayan podido pasar por alto a muchos teólogos por tanto tiempo, ahora que la Instrucción afirma el carácter radicalmente cristiano y teológico de la liberación y la necesidad consiguiente de hacer una teología de la liberación, aunque entendida todavia como una forma regional de la teologia, como una parte de la teología y no como una perspectiva nueva de toda la ieologia.

La Instrucción comienza diciendo que "el evangelio de Jesucristo es un mensaje de libertad y una fuerza de liberación. En los últimos años esta verdad esencial ha sido objeto de reflexión por parte de los teólogos con una nueva atención rica de promesas" (Introducción). La primera parte de la primera afirmación no ha dejado de reconocerse desde antiguo, aunque con evidentes limitaciones precisamente porque no se han puesto en la debida conección libertad y liberación; es en la segunda parte de esa primera frase donde está la novedad: el evangelio de Jesucristo es una fuerza de liberación. A ambas partes de la afirmación se las considera como 'verdad esencial' aunque sólo en los últimos anos parece haberse visto como tal, a pesar de su esencialidad; 0 , al menos, solo en los últimos años ha sido tomada por los teblogos como objeto de reflexión "con una nueva atención rica de promesas."

¿Qut es lo que ha pasado para que surja esta notable novedad teológica?

Digitalizado por Biblioteca "P. Florentino Idoate, S.J."

Universidad Centroamericana "José Simeón Cañas" 
"La poderosa y casi irresistible aspiración de los pueblos a una liberación constituye uno de los principales signos de los tiempos que la Iglesia debe discernir $e$ interpretar a la luz del evangelio" (I. 1). Esta aspiración, reconoce la Instrucción se expresa con fuerza "sobre todo en los pueblos que conocen el peso de la miseria y en el seno de los estratos sociales desheredados" (ib. 1) La Instrucción no se pregunta por qué, pero en su constatación hace avances de singular importancia: la liberación que constituye uno de los principales signos de los tiempos se hace presente sobre todo en los pueblos que conocen el peso de la miseria y en los estratos sociales desheredados. Esto significa al menos los siguientes puntos: a) la liberación tiene en su modo concreto de presentarse una componente claramente histórico-social, pues se trata, en un primer momento, de una liberación de la miseria y del estar des-heredados; b) su lugar propio de aparecer es el de los miserables y desheredados y no el de los ricos desheredantes quienes más bien propendian a no ver y aun a oscurecer la jisticia y la necesidad de la liberación; c) es en cuanto liberación socio-histórica un signo de los tiempos, uno de los principales signos de los tiempos, que habia pasado inadvertido en cuanto signo de los tiempos, a pesar de haberse cstado dando desde hace muchísimos años como aspiración y a pesar de tener un riquisimo contenido teologal, que la propia Instrucción recoge aprovechándose de las reflexiones que sobre este punto habian hecho los teólogos de la liberación; d) es una de las tareas más importante a las que se deben dedicar los hombres por su alto contenido ético y teologal.

Conviene insistir sobre qué clase de liberación es la que se constituye inicialmente en signo de los tiempos, la cual se debe discernir e interpretar a la luz del evangelio. Es liberación de "las múltiples opresiones culturales, políticas, raciales, sociales y económicas" $(I, 2)$, del "aplastamiento de la miseria con sus secuelas de muerte, enfermedades y decadencias" $(1,4)$, del "escándalo de irritantes desigualdades entre ricos y pobres...," de "la privación de los bienes de estricta necesidad, de suerte que no es posible contar el número de las víctimas de la mala alimentación" ( 1,6$)$; de "la ausencia de equidad y de sentido de la solidaridad en los intercambios internacioanles..." ( $(1,7)$; de "la gigantesca carrera de armamentos que, junto arlas amenazas contra la paz, acapara sumas enormes de las cuales una parte solamente bastaría para responder a las necesidades más urgentes de las poblaciones privadas de lo necesario" $(1,9)$. En esta descripción de la liberación, en cuanto se refiere a aquello de lo que el hombre debe ser liberado, es claro que el acento, por no decir todos y cada uno de los contenidos, es lo que define la liberación socio-histórica. En esta parte de la Instrucción no se tocan otros aspectos que deben ser objeto de liberación, más allá de la liberación socio-histórica que abarca lo político y lo económico, pero que también toma en cuenta aspectos muy opresores de las relaciones entre los hombres, entre los grupos sociales y entre las naciones. Que la Instrucción haya subrayado los más económicos y sociales no deja de ser significativo.

Vista asi la liberacion, se dice de ella que es un "tema cristiano," que consecuentemente se convierte no sólo en tema teológico, sino más ampliamente en una nueva teología o más bien distintas teologias, que son las teologias de la 
liberación. El que la Instrucción sostenga que algunas de ellas son peligrosas desde el punto de vista de la fe - punto que examinaremos más adelante- no obsta para reconocer la necesidad de responder teológicamente a esta aspiración universal y masiva de los pueblos y de los sectores sobre los que se abate la miseria de la pobreza. Repitamos aqui una vez más que la pobreza y la miseria de las que se parte al hablar de la liberación son una realidad histórica constatable, la sufren los pueblos más pobres por sus relaciones desiguales con los más ricos y también la sufren los sectores desheredados. No se hace aqui el socorrido artificio de ampliar el concepto de pobreza para introducir en él a todos los que sufren, cuando no a todos los que la profesan en espiritu. Las reflexiones teológicas o simplemente cristianas sobre la liberación arrancan de la constatación y de la vivencia de la pobreza material, tal como se da masivamente entre los hombres de nuestro liempo en contraste con la riqueza de unos pocos.

Aun tomada con esá crudeza se dice que la liberación es un tema fundamental del Antiguo y del Nuevo Testamento. A pesar de este reconocimiento (III, 7), no se nos explica por qué ha desempeñado tan poco papel en la historia de la teologia, al menos de la teología académica. Hoy, al menos, se considera urgente recuperar el tiempo perdido y hacer una teología o una parte de ella que pueda considerarse como una auténtica leologia de la liberación. De ella se da una definición provisional que resulta parcial: "designa entonces una reflexión teológica centrada sobre el tema biblico de la liberación y de la libertad, y sobre la urgencia de sus incidencias prácticas" (III, 4). No es poco lo que en esta descripción se dice, si se entiende bien. El problema está en delimitar qué significa ese termino de "centrada." Puede significar que el tema de la libertad y de la liberación se convierta en problema importante, en uno de los problemas centrales de la teologia; esto ya seria un gran avance, pues en el mejor de los casos se ha tratado el tema de la libertad sin verlo desde la perspectiva de la liberación y además se lo ha tratado muchas veces como si no fuera realmente uno de los problemas centrales. Pero ese término "centrada" puede entenderse aún con mayor rigor: se irataria de estudiar todos los temas usuales de la teologia, no excluidos ni siquiera los estrictamente trinitarios, desde una perspectiva central que sería la de la libertad-liberacion, aunque en este caso ni siquiera la libertad-de, esto es, la liberación, se reduciria a una liberación exclusivamente socio-histórica, y mucho menos la libertad-para o la libertad-hacia quedarian reducidas a conseguir un ordenamiento humano del cual hubiera desaparecido la injusticia social. Este segundo sentido es el que más se acerca a lo que con el término de teologia de la liberación se hace en América Latina por los más usualmente considerados teólogos de la liberación, tal vez aquellos a los que Monseñor Quarracino engloba en "la corriente más notoria de la teología de la liberación," 16 que, sin embargo, no cae en la marxistización que él le atribuye como más tarde veremos. Como quiera que sea, el que la Instrucción reconozca que pueda y deba darse una teologia de la liberación que centre su reflexión sobre el tema biblico de la libertad " $y$ " de la liberación, bíblico no en el sentido exclusivo de ver lo que hay de libertad y liberación en la Biblia, sino lo que desde la Biblia se puede ver integralmente sobre libertad y liberación; el que, además, reconozca que esa reflexión deba centrarse también en la ur- 
gencia de sus incidencias prácticas no sólo individuales, sino sociales, como objeto de reflexión estrictamente teo-lógica y no meramente ética, por más que sea una ética de inspiración cristiana, constituyen ya un apoyo oficial del magisterio que hasta ahora no se tenia de un modo tan explicito.

La teologia de la liberación es una necesidad, además de ser ya un hecho nacido como la Instrucción reconoce "en primer lugar en los paises de América Latina, marcados por la herencia religiosa y cultural del cristianismo" (III, 2). Por ser un hecho y una necesidad es tan urgente evitar que caiga en desviaciones. Si no fuera tan importante y tan necesario lo que lleva entre manos la teologia de la liberación, no tendria sentido esta seria llamada de atención que hace la congregación para la doctrina de la fe. El haber logrado los teólogos latinoamericanos que estos temas centrales de la fe cristiana, bastante descuidados por otras teologías, sean recuperados para el acervo cristiano y para el desafio del mundo actual, es ya un mérito indiscutible y reconocido de una forma o de otra no sólo por muchos creyentes de todo el mundo ni sólo por un gran número de teólogos competentes, sino por el magisterio de la Iglesia tanto local como universal.

Dos son las razones principales de esta necesidad. La primera que sin ella quedan desdibujados algunos temas centrales de la fe. Entre estos temas la Instrucción recuerda "la experiencia radical de la libertad cristiana" (IV, 2); la experiencia de los distintos éxodos del pueblo elegido que llevan a la experiencia de Dios como liberador (IV, 3 y 4); el significado de los "pobres del Señor" (IV, 5); las exigencias de la justicia y de la solidaridad que llevan a "un juicio extremadamente severo sobre los ricos que oprimen al pobre" y que colocan a la justicia en estrecha relación con la fidelidad a la alianza; la radicalización que el Nuevo Testamento hace de las exigencias del Antiguo, sobre todo en lo que toca a la pobreza, la identificación de los pobres y perseguidos con el mismo Cristo, las recriminaciones a los ricos, un nuevo sentido del pecado y de la relación entre el pecado social y el pecado estructural, una nueva relación de la justicia con la misericordia desde la regla suprema del amor, entre otros muchos que pudieran señalarse (IV, 7-15).

La segunda razón principal es que sin la teologia de la liberación no se sitúa al cristianismo en la verdadera línea de su compromiso en la superación de la injusticia y de la miseria. Ciertamente esto lo ha hecho de alguna forma el magisterio de la Iglesia a través de numerosos documentos. La Instrucción recuerda expresamente las enciclicas Mater et Magistra, Pacem in terris, Populorum progressio y con ellas la Octogesima adveniens. Tambièn recuerda la constitución pastoral Gaudium et Spes del Vaticano II. De Juan Pablo II recoge las encíclicas Redemptor hominis, Dives in misericordia y Laborem exercens, así como el discurso pronunciado ante la XXXVI Asamblea General de la ONU el 2 de octubre de 1979. También se recuerdan las dos ocasiones en que el Sínodo de los Obispos (1971 y 1974) ha tratado el problema de la justicia en el mundo y el de la relación entre la liberación de las opresiones y la liberación integral o la salvación del hombre y la respuesta a esas preocupaciones en la Evangelii nuntiandi. También señala como muy importantes los documentos de Medellin y de Puebla. No han faltado, pues, documentos eclesiásti- 
cos en los últimos veinte años sobre la injusticia y la necesidad de su superacion. Pero que esto no ha sido suficiente lo demuestra, por un lado, la existencia misma de una poderosa teologia de la liberación que no hubiera tenido sentido ni aceptación universal si es que se hubiera situado en la misma linea de la doctrina social de la Iglesia y, por otro lado, la falta de operativización adecuada de las demandas de la Iglesia, no sólo fuera de ella, sino en su mismo seno, donde la opción preferencial por los pobres no ha sido su nota distintiva ni siquiera en aquellos paises donde la presencia de los pobres es mayoritaria y su condición absolutamente inhumana.

La teologia de la liberación, en tanto que teologia, se ha convertido asi en uno de los instrumentos teóricos eclesiales más fuertes para cumplir con la misión ineludible de la liberación integral de todos los hombres, pero especialmente de las mayorias oprimidas de todo el mundo. Ella ayuda no sólo a superar el pecado de la injusticia, sino que anima a la liberación integral, que precisamente por serlo no puede dejar de partir de la existencia histórica de la opresión y de la represión; no sólo realiza una tarea estriclamente cristiana, sino que hace creíble la fe en primer lugar a los pobres, a quienes va especialmente dirigido el mensaje evangélico, pero también al resto de los hombres, responsables de una forma o de otra de la pobreza imperante en el mundo. Mientras otro tipo de teologia trataba de hacer creible la le a los sabios y poderosos de este mundo, porque a los pobres se la imponian con frecuencia instilucional o socialmente; la teologia de la liberación trata de hacer creible y operante la fe a las mayorias populares y en ese signo escandaloso la hace también creíble para las minorias, sean éstas académicas, económicas, culturales o politicas.

Mientras se den situaciones como las que la misma Instrucción estigmatiza tan certeramente cuando dice: "En ciertas regiones de América Latina, el acaparamiento de la gran mayoría de las riquezas por una oligarquia de propietarios sin conciencia social, la casi ausencia o las carencias del Estado de derecho, las dictaduras militares que ultrajan los derechos elementales del hombre, la corrupción de ciertos dirigentes en el poder, las prácticas salvajes de cierto capital extranjero, constituyen otros tantos factores que alimentan un violento sentimiento de revolución en quienes se consideran victimas importantes de un nuevo colonialismo de orden tecnológico, financiero, monetario o económico..." (VII, 12), una teologia que tome absolutamente en serio esta realidad, negadora de la paternidad divina, de la filiación sobrenatural, de la animación del Espiritu, será absolutamente necesaria. Y ninguna otra teología lo ha hecho hasta ahora como lo ha hecho la teologia de la liberación, que sin haber llegado todavia a su plenitud y sin haber podido superar sus propias limitaciones de un modo perfecto, ha hecho ya mucho por la fe y por la vida de las mayorias populares del continente.

\section{Algunas formas inaceptables de teologia de la liberación}

Tanto la Instrucción como la presentación oficial que de ella hizo Monseñor Quarracino reconocen que siendo necesaria la teologia de la liberación, hay muy diversas formas de entenderla, de las cuales unas son aceptables y otras no lo son. Asi la teología de la liberación que subyace a Puebla y aun 
aquella que no usa el análisis marxista, sino más bien un método históricocultural, serian aceptables, pero no lo es la que subyace al movimiento "cristianos por el socialismo."17 Curiosamente el presidente del CELAM no habla aquí de la teología subyacente a Medellin, la cual es, desde luego, la fundamental y a la cual él llama "la corriente teológica que comúnmente se denomina con el nombre de "leología de la liberacion," 18 y a cual considera hace alusión la Instrucción. Sin embargo, como ésta evita citar autores y obras y elige el método de caracterizar objetivamente lo que es inaceptable, es preferible dejar de momento el problema de a qué teólogos y/u obras se refiere la Insıruccion para subrayar qué teología de la liberación sería inaceptable doctrinalmente desde el punto de vista del magisterio. Aqui está el punto principal de la Instrucción en cuanto documento del magisterio y por eso conviene atenderlo de manera muy especial.

En un primer momento se subraya como inaceptable aquella orientacion que pone "el acento de modo unilateral sobre la liberación de las esclavitudes de orden terrenal y temporal, de tal manera que parecen hacer pasar a un segundo plano la liberación del pecado, y por ello no se la atribuye prácticamente la importancia primaria que le es propia... Además, con la intención de adquirir un conocimiento más exacto de las causas de las esclavitudes que quieren suprimir, se sirven, sin suficiente precaución crítica, de instrumentos de pensamiento que es dificil, e incluso imposible, purificar de una inspiracion ideologica incompatible con la fe cristiana y con las exigencias éticas que de ella derivan" (Introducción). Se trata, pues, de evitar la unilateralidad que supondria quedarse en la liberación de las esclavitudes de orden temporal y terrenal sin dar el relieve debido a la liberación del pecado, y, en segundo lugar, se trata de evitar el uso no crítico de instrumentos de pensamiento incompatibles con la fe y con las exigencias derivadas de ella. Una teología de la liberación que cayera en estos dos extremos no seria aceptable ni podría alcanzar los objetivos que debe tener la teología de la liberación, cuya necesidad ya hemos mostrado antes. Nada hay que objetar a estos dos puntos en sí mismos; donde quiera se caiga, en uno u otro de ellos, cuando no en los dos, estamos ante algo que ha de ser superado o abandonado. El problema estribará en determinar cuándo ocurre esto, pues al parecer ningún teblogo cristiano asume como principio de su quehacer teológico el circunscribir la liberación en esos términos ni el usar instrumentos incompatibles con la fe. Pero de esta misma formulación conviene sacar consecuencias indirectas: aquellas teologías que desconozcan la importancia cristiana y aun teológica de la liberación de las esclavitudes terrenales no son teologías aceptables, pues desconocen al menos exigencias derivadas de la fe que serian o negadas o simplemente olvidadas; en segundo lugar, no ha de pensarse que sólo la teología de la liberación usa instrumentos de pensamiento y olvidarse de que los usados por otras teologias pueden ser también, si no se usan críticamente, incompatibles con la fe o con las exigencias de la fe. Tal pudiera ser el caso, por ejemplo, de los análisis de las teorias funcionalistas que sustentan muchas de las concepciones utilizadas incautamente en las aplicaciones de la fe a las realidades sociales. Los principios usados en la Instrucción ponen en guardia contra un abuso y otro, aunque en ella sólo se subraye uno de los abusos posibles. 
Estos dos puntos son analizados más largamente a lo largo de la Instrucción. Trataremos, en primer lugar, el que se refiere a las limitaciones y desviaciones que harian de cualquier teologia algo inconciliable con la fe cristiana, para, en un segundo momento, aplicar nuestra reflexión al uso de instrumentos concepluales que según la instrucción son los tomados del marxismo.

\subsection{Limilaciones y desviaciones inaceptables}

La teología de la liberación, en cuanto designa "una preocupación privilegiada, generadora del compromiso por la justicia, proyectada sobre los pobres y las víctimas de la opresión" (III, 3), es, como vimos, algo necesario. Lo que sucede es que sus l'ronteras doctrinales están todavía mal definidas, lo cual haría que pudiese caer en formulaciones teológicas inaceptables.

Una primera preocupación es el abandono y/o reducción de la idea de pecado: "La primera liberación, a la que han de hacer referencia todas las otras, es la del pecado" ( $\mathrm{VI}, 7)$. "Consecuentemente no se puede restringir el campo del pecado, cuyo primer efecto es introducir el desorden en la relación entre el hombre y Dios, a lo que se denomina 'pecado social" " $(I V, 12)$. "No se puede tampoco localizar el mal principal y únicamente en las 'estructuras' económicas, sociales o políticas malas, como si todos los otros males se derivasen, como de su causa, de estas estructuras..." (IV, 15).

Esta reducción se desprendería de una reducción previa, por la que "el Evangelio se reduce a un evangelio puramente terrestre" (VI, 4), lo cual lleva a abandonar la evangelización en favor de la liberación material inmediata, puesto que la lucha por la justicia y la libertad humana, entendidas en su sentido económico y politico, constituirían "lo esencial y el todo de la salvación" (ib.). Se habria ido demasiado lejos en la historización de la fe y de la salvación. Se afirmará que Dios se hace historia. Se añadiria que no hay más que una sola historia, en la cual no hay que distinguir ya entre historia de la salvación e historia profana... Por eso se tiende a identificar el Reino de Dios y su devenir con el movimiento de la liberación humana... Esta identificación está en oposición con la fe de la Iglesia, tal como lo ha recordado el Concilio Vatino Il" (IX, 3). "En esta línea, algunos llegan hasta el límite de identificar a Dios y la historia, y a definir la fe como "fidelidad a la historia," lo cual significa fidelidad comprometida en una práctica politica..." (IX, 4). "De esta concepción se sigue inevitablemente una politización radical de las afirmaciones de la fe y de los juicios teológicos... Se trata... de la subordinación de toda afirmación de la re o de la teologia a un criterio político..." (IX, 6). En esta descripción de una hipotética teología de la liberación se rechazan puntos que con razón deben ser rechazados. Tales serian: a) la identificación del reino de Dios y su devenir con el movimiento de liberación humana de las esclavitudes (errestres, de suerte que serian una y la misma cosa; b) la identificación todavia más grave de Dios e historia, de suerte que fueran una y la misma cosa; c) la subordinación total de las afirmaciones de la fe o de la teologia a un criterio puramente politico; d) el abandono de la idea de pecado; e) la reducción del pecado al pecado social; $\eta$ el abandono de la evangelización y entrega total a la 
liberación terrenal. No hay problema alguno en rechazar como no cristianas ni compatibles objetivamente con la fe todas y cada una de esas afirmaciones, sin que ello suponga rechazar la conexión necesaria del reino de Dios con la liberación humana, de Dios con la historia, de las afirmaciones de la fe y de la teología con significados politicos, del pecado en su referencia a Dios con el pecado en su referencia al hombre, del pecado personal con el pecado social, de la evangelización con la liberación. La Instrucción afortunadamente insiste en esta conexión, punto que hasta ahora no habia sido siempre debidamente considerado y sobre todo llevado a la práctica.

Con mucho mayor cuidado han de comarse algunas expresiones que parecerian indicar como insostenible que Dios se hace historia o que hay una sola historia. Sobre este punto ya escribi con más detención en otro lugar y a él me remito. ${ }^{19}$ El que Dios se haya hecho historia antes, en y después de haberse hecho hombre en Jesús es una afirmación perfectamente ortodoxa, hasta el punto de que si no se la mantiene en alguna forma se cae en un teísmo que nada tiene de cristiano. El que sólo se dé una historia sin que por ello se anule la transcendencia de la historia de la salvación es tambièn perfectamente sostenible. La exageración de esta doble afirmación puede llevar a errores, pero su negación exagerada también puede y de hecho ha llevado a cometerlos. Hay todavia mucho que trabajar sobre estos puntos para no caer en simplismos, sean estos dualistas o monistas, pero no se puede aceptar que sólo uno de los lados esté en peligro de desviarse. Quien mantenga coherenternente lo que se ha dicho y defendido en el párrafo inmediatamente anterior no se ha desviado, sino que está en la línea de encontrar teórica y prácticamente nuevas explicitaciones de la fe y de las exigencias prácticas de la fe.

También por lo que toca a la cristología se advierten serias desviaciones, que harian del todo rechazable la teología de la liberación que en ellas incurriere: "privilegiando de esta manera la dimensión politica, se ha llegado a negar la radical novedad del Nuevo Testamento y, ante todo, a desconocer la persona de Nuestro Señor Jesucristo, verdadero Dios y verdadero hombre, al igual que el carácter específico de la liberación que nos aporta..." (X, 7). "Sin espiritu critico se vuelve a la oposicion entre el Jesús de la historia y el Jesús de la $f e$ " $(\mathrm{X}, 8)$. "Es cierto que se conservan literalmente las fórmulas de la fe, enparticular la de Calcedonia, pero se le atribuye una nueva significación, lo cual es una negación de la fe de la lglesia" $(X, 9)$. "Está claro que se niega la fe en el Verbo encarnado, muerto y resucitado por todos los hombres y que "Dios ha hecho 'Sentor y Cristo"' (ACl 2, 36). Se le substituye por una "Iigura" de Jesús que es una especie de símbolo que recapitula en si las exigencias de la lucha de los oprimidos" $(\mathrm{X}, 11)$. "Así se da una interpetación exclusivamente politica de la muerte de Cristo. Por ello se niega su valor salvifico y toda la economía de la redención' $(X, 12)$.

Si exceptuamos en el anterior elenco la afirmación metodológica de que es posible mantener con espíritu crítico la distinción (oposición, dice el texto) entre el Jesús de la historia y el Jesús de la fe, nos encontramos efectivamente con una serie de herejías, inaceptables para cualquier teb́logo cristiano. Se trataria, en definitiva, de afirmaciones que niegan o desfiguran la divinidad de 
Jesús y el carácter estrictamente salvífico de la redención. Al parecer la Instrucción se refiere a casos concretos, que no cita y menos documenta, pues acepta que los encausados mantienen las fómulas cristológicas tradicionales, aunque vaciadas de su sentido real.

De manera semejante se recogen afirmaciones eclesiológicas que serian del todo punto inaceptables a la hora de hacer una teologia de la liberación plenamente cristiana en continuidad con la tradición. "En cuanto a la Iglesia, se tiende a ver en ella sólo una realidad interior de la historia... Esta reducción vacia la realidad específica de la Iglesia, don de la gracia de Dios y misterio de fe..." (IX, 8). Y en cuanto a la lglesia de los pobres se pervierte el sentido cristiano del pobre para convertirlo en el proletariado de Marx. "La Iglesia de los pobres significa asi una Iglesia de clase, que ha tomado conciencia de las necesidades de la lucha revolucionaria como etapa hacia la liberacion y que celebra esta liberación en su liturgia" (IX, 10). Paralelamente se entiende como Iglesia del pueblo "una Iglesia de clase, la lglesia del pueblo oprimido que hay que 'concientizar' en vista de la lucha liberadora organizada. El pueblo asi entendido llega a ser también para algunos, objeto de fe" $(1 \mathrm{X}, 12)$. Con ello "se trata de poner en duda la estructura sacramental y jerárquica de la Iglesia, tal como la ha querido el Señor. Teológicamente, esta posición vuelve a decir que el pueblo es la fuente de los ministerios y que se puede dotar de ministros a elección propia, según las necesidades de su misión revolucionaria histórica"' (IX, 13). "La jerarquia, y sobre todo el Magisterio romano son así desacreditados $a$ priori, como pertenecientes a la clase de los opresores" $(\mathrm{X}, 1)$.

En todas estas condenaciones se reconoce, sin embargo, que se ha de insistir en el carácter histórico de la Iglesia, en la necesidad de enfocar correctamente la Iglesia como una Iglesia de los pobres y una Iglesia del pueblo, lo cual vuelve a probar no sólo la importancia de la teologia de la liberación en cuanto ha hecho de estos y otros temas objeto principal de su reflexion, cosa que no sucedia en otras teologías, sino la necesidad de que se continúe haciendo una teologia de la liberación que, sin caer en los defectos apuntados por la Instrucción, desarrolle esos puntos esenciales tantas veces olvidados o minusvalorados por otras teologias que insistiendo correctamente en lo que la Instrucción señala como más propio de la tradición han descuidado, no obstante, algunos aspectos esenciales.

También respecto de los sacramentos se señalan deficiencias o errores que no pueden ser aceptados en ninguna teologia de la liberación. En general se trata de una inversión de los simbolos. "La Eucaristía ya no es comprendida en su verdad de presencia sacramental del sacrificio reconciliador y como el don del Cuerpo y de la Sangre de Cristo. Se convierte en celebración del pueblo que lucha" $(X, 16)$. "En lugar de ver con S. Pablo, en el Exodo, una figura del bautismo (1 Cor 10, 1-2), se llega al limite de hacer de él un simbolo de la liberación política del pueblo" $(X, 14)$.

Con las virtudes teologales ocurre algo similar. "La fe, la esperanza y la caridad reciben un nuevo contenido: ellas son 'fidelidad a la historia', 'confianza en el futuro', 'opción por los pobres': que es como negarlas en su rea- 
lidad teologal" (IX, 5). Aqui tampoco el mal está en sacar las consecuencias politicas de lo que son la fe, la esperanza y la caridad cristianas, sino en reducir estas virtudes a su significado politico vaciándolas de todo sentido trascendente.

Ya en lo que se refiere a puntos muy importantes para la praxis cristiana, pero menos estrechamente relacionadas con la revelación, la Instrucción insiste que se yerra en la concepción misma de la verdad al pretender "que soblo hay verdad en y por la praxis partidaria" (VIII, 4). "De hecho, el carácter transcendente de la distinción entre el bien y el mal, principio de la moralidad, se encuentra implícitamente negado en la óptica de la lucha de clases" (VIII, 9).

No pretendemos discutir lodavia si algunas de las principales teologias de la liberacion tal como han sido cultivadas y expresadas por los principales teólogos de la liberación caen en algunos de estos errores dogmáticos, cosa que parece afirmar tanto la Instrucción misma como la presentación que de ella hizo Monseñor Quarracino. Volveremos sobre ello más tarde. Aquí baste con asegurar que una teologia de la liberación que cayera en esos errores no seria una teología de la liberación cristiana, de la que tanta necesidad tiene la lglesia entera como mostramos sucintamente en el primer apartado de este articulo. Lo que sigue siendo preocupante es que se vean estos graves errores en textos y autores que reconociendo la dimensión liberadora de la fe no se apartan en ningún momento de esa fe, aunque la formulan de un modo más integral.

\subsection{Teologia de la liberación y análisis marxjsta}

La Instrucción insiste en que no quiere tratar de todas las teologías de la liberación, sino sólo de una especie de ellas, la que está fuertemente inficionada de marxismo. Aunque parte de los errores condenados se deben a una "hermenética bíblica dominada por el racionalismo," su principal raiz está en "préstamos no criticados de la ideologia marxista" (VII, 10). Para analizar este punto importante dividiremos la cuestión en dos partes: en la primera, estudiaremos qué concepción del marxismo tiene la lnstrucción y, en la segunda, los influjos mismos del marxismo sobre la teologia de la liberación.

\subsubsection{El análisis manxlsta según la Insirucción}

" 'El pensamietno de Marx constituye una concepción totalizante del mundo en la cual numerosos datos de observación y de análisis descriptivo son integrados en una estructura filosófica-ideológica, que impone la significación y la importancia relativa que se les reconoce. Los a priori ideológicos son presupuestos para la lectura de la realidad social. Así, la disociación de los elementos heterogéneos que componen esta amalgama epistemológicamente hibrida llega a ser imposible, de tal modo que creyendo aceptar solamente lo que se presenta como un análisis, resulta obligado aceptar al mismo tiempo la ideología" (VII, 6). "Recordemos que el ateismo y la negación de la persona humana, de su libertad y de sus derechos, están en el centro de la concepción marxista... El desconocimiento de la naturaleza espiritual de la persona conduce a subordinarla totalmente a la colectividad y, por tanto, a negar los princi- 
pios de una vida social y política conforme con la dignidad humana" (VII, 9). "En la lógica del pensamiento marxista, 'el análisis' no es separable de la praxis y de la concepción de la historia a la cual está unida esta praxis. El análisis es asi un instrumento de crítica, y la crítica no es más que un momento de un combate revolucionario. Este combate es el de la clase del Proletariado investido de su misión histórica" (VIII, 2). "En consecuencia sólo quien participa en este combate puede hacer un análisis correcto" (VII, 3) "La conciencia verdadera es asi una conciencia partidaria..." (VIII, 4). "La praxis, y la verdad que de ella derivan, son praxis y verdad partidarias, ya que la estructura fundamental de la historia está marcada por la lucha de clases..." (VIII, 5). "La ley fundamental de la historia que es la ley de la lucha de clases implica que la sociedad está fundada sobre la violencia. A la violencia que constituye la relación de dominación de los ricos sobre los pobres deberá responder la contra-violencia revolucionaria mediante la cual se invertirá esta relación" (VIII, 6). "La lucha de clases es pues presentada como una ley objetjva, necesaria. Entrando en su proceso, al lado de los oprimidos, se 'hace' la verdad, se actúa 'cientificamente'. En consecuencia, la concepción de la verdad va a la par con la afirmación de la violencia necesaria, y por ello con la del amoralismo politico. En estas perspectivas, pierde todo sentido la referencia a las exigencias éticas que ordenan reformas estructurales $e$ instilucionales radicales y valerosas" (VIII, 7). "La ley fundamental de la lucha de clases tiene un carácter de globalidad y de universalidad. Se relleja en todos los campos de la existencia, religiosos, éticos, culturales e institucionales. Con relación a esta ley ninguno de estos campos es autónomo. Esta ley constituye el elemento determinante en cada uno" (VIII, 8). "De hecho, el carácter transcendente de la distinción entre el bien y el mal, principio de la moralidad, se encuentra implicitamente regado en la óptica de la lucha de clases" (VIIl, 9).

Reconoce la Instrucción que el pensamiento marxista se ha diversificado "para dar nacimiento a varias corrientes que divergen notablemente unas de otras," pero inmediatamente advierte que "en la medida en que permanecen realmente marxistas, estas corrientes continúan sujetas a un cierto número de tesis fundamentales que no son compatibles con la concepción cristiana del hombre y de la sociedad" (VII, 8). Al parecer -en esto la Instrucción no es científicamente muy rigurosa ni es suficientemente critica- esas tesis fundamentales son las que hemos transcrito en el párrafo anterior.

Es en esta descripción del marxismo donde la lnstrucción tiene uno de sus flancos más débiles desde el punto de vista histórico y desde el punto de vista epistemológico. Definir que tales o cuales tesis, provengan de donde provengan, son inconciliables o dificilmente conciliables, según los casos, con la fe, es algo que entra en la competencia del magisterio; decir en cambio que tales o cuales tesis pertenecen a una escuela de pensamiento y en ella son esenciales o no, son separables o no, es algo para lo que el magisterio no tiene competencia especial. En ese aspecto sus afirmaciones valdrán lo que valgan sus razones. La historia del magisterio de la Iglesia, incluso del reciente magisterio de la Iglesia, cuando no es definitivo, se ha visto enturbiada por posiciones que hoy resultan insostenibles, precisamente por haberse metido en terrenos más o menos 
cientificos donde la falseabilidad de una afirmación puede mostrarse, y haber pretendido determinar incompatibilidades, que luego se han visto no eran tales. Hubiera sido mejor haber dicho que no se ve como puedan conciliarse dos afirmaciones, una científica y otra teológica - casos de Galileo, del evolucionismo, del poligenismo, de la democracia y de los derechos humanos, de la revolución francesa o de la independencia de Latinoamérica, de los autores de los libros sagrados, etc...- que no el definir incompatibilidades que después refluyen en desprestigio del mismo magisterio.

Desde este punto de vista cabe aceptar que tal o cual manual marxista e incluso prácticas usuales del socialismo real caigan mucho o poco en lo que sefhala la Instrucción. Pero es más que discutible que esas afirmaciones sean válidas del marxismo, y, menos aún, del propio Marx. Algunas lo son y otras no, algunas lo son en mayor medida que otras. La valoración crítica deja, por tanto, mucho que desear.

Por lo que toca a aspectos más filosóficos, no es sostenible sin más que "el atelsmo y la negación de la persona humana, de su libertad y de sus derechos, están en el centro de la concepción manxista." El ateísmo, muchas veces profesado por el materialismo dialéctico, no es en nada necesario para el materialismo histórico. Por razón del atelsmo nada fundamental de los Grundrisse o de El capital p!rede ser negado, porque no está conectado necesariamente ni siquiera convencionalmente. Decir, además, que la negación de la persona humana, de la libertad y de los derechos humanos pertenece al centro de la "concepción marxista" es insostenible. Tal vez lo sea una determinada concepción individualista de la persona humana, una concepción liberal de la libertad, una concepción burguesa de los derechos; tal vez sean discutibles el sentido y el valor que se dan en el marxismo -en muchas de sus formas- a la persona, a la libertad y al derecho, pero de ahí concluir que se los niega y que esa negación pertenezca a su centro, no es acertado. Recordemos, porque lo hace también la Instrucción, cómo se ha sido de tolerante con la esclavitud dentro de la concepción cristiana, cómo el magisterio romano ha negado en siglos pasados algunos de esos derechos humanos que hoy niegan también algunas formas de socialismo real; sin embargo, no concluiremos de ahi que la negación de la libertad y de los derechos humanos está en el centro del mensaje cristiano.

Por lo que toca a aspectos epistemológicos, la relación entre praxis y teoria es mucho más compleja en el marxismo de lo que simplificadamente senala la Instrucción. Probablemente pueden encontrarse textos marxistas de importancia que apunten en esa dirección, pero más en textos políticos que en textos filosóficos, en manuales más que en fuentes. Bastaría para probarlo una lectura crítica de El capiral e incluso una lectura del libro de Lenin Materialismo y empiriocriticismo para mostrar métodos y resultados, que no se reflejan bien en la descripción que del marxismo hace la Instrucción. Y esto es mucho más verdadero en los llamados marxismos heterodoxos. Puede reconocerse que hay exageraciones y peligros al insistir en la primacía de la praxis, pero hay también graves exageraciones y peligros al no analizar adecuadamente las complejas relaciones de ida y vuelta entre teoria y praxis. 
Por lo que toca a la interpretación de la historia desde la lucha de clases la Instrucción es asimismo poco critica y matizada. Hay pocas dudas sobre la importancia que Marx atribuyó a la lucha de clases como motor de la historia al menos tras la aparición de la burguesia; punto, sin embargo, que algunos marxismos contemporáneos van abandonando, tanto en el modo de entender las clases y el proletariado como la lucha misma, aunque entendiendo el abandono como transformación más que como anulación. Pero la lucha de clases tal como es presentada en la Instrucción cae en simplificaciones y exageraciones impropias de un documento magisterial, escrito en nuestros días. Ciertamente algunas organizaciones populares que se profesan marxistas-leninistas repiten mecánicamente un manxismo trasnochado que se amolda bastante bien a esa descripción. Desde este punto de vista puede ser útil la advertencia que se hace. Pero es un punto de vista que debiera ser superado, porque en definitiva sólo un marxismo superado, que en su superacion recoja lo mejor de él, puede sobrepasar etapas más toscas y radicales de marxismo que son las que han entrado en conflicto con la fe cristiana. Y este proceso de superación, en vez de ser favorecido por posiciones como las que se muestran en la Instrucción, se ve dificultado tanto desde un punto de vista teórico como pastoral. A su vez posiciones primitivas y toscas de marxismo, recogidas a veces por organizaciones entre cuyos miembros hay muchos cristianos, dan base para que se hagan condenas globales no sólo del marxismo, sino tambien de la propias organizaciones. Sin negar que hay situaciones muy distintas y que lo que parece ya inaplicable, tanto en el análisis teórico como en la praxis política en sociedades más desarrolladas, puede ser todavía de aplicación en sociedades más próximas a las descritas por Marx y Engels en el siglo XIX. Si la lucha de clases va a significar un enfrentamiento movido por el odio entre grupos humanos que sólo pueden superar sus conflictos por la violencia armada en busca de que los dominados pasen a ser dominadores, se tratarla de algo no aceptable por los cristianos; pero tal descripción es no sólo simplifcadora de la teoría y de la praxis marxista, sino falsificadora de las mismas, si tomamos las cosas en su conjunto.

La propia Instrucción reconoce como hecho un concepto equivalente al de lucha de clases, sólo que con él quiere retirar las resonancias que la lucha de clases recibe por su contexto marxista. Es, por un lado, el concepto de "conflicto social agudo" (VII, 19) y, por otro, la descripción que hace del mismo en el párrafo antes transcrito (VII, 12). En éste se habla de una oligarquía de propietarios sin conciencia social que acapara la gran mayoría de las riquezas, de las prácticas salvajes de cierto capital extranjero y en contrapartida de las "víctimas impotentes de un nuevo colónialismo de orden tecnológico, financiero, monetario o económico" (ib.). A este hecho histórico en ciertas regiones de América Latina, no se le llama en la Instrucción lucha de clases ni siquiera conflicto entre el capital y el trabajo tal como se hace en la Laborem execens, pero se lo muestra como la expresión de una realidad en donde unos están enfrentados con otros en razón de la propiedad hasta constituirse en oligarquía de una parte y de grandes mayoras injustamente tratadas de otra. La Instrucción no se detiene a explicar científicamente por que esto es así y a traves de que mecanismo ocurre. Prefiere saltar de esa mediación a la malicia del corazón humano 
dañado por el pecado personal. Pero este salto no quita que deba preguntarse, como lo acepta la misma lnstrucción, por las causas de estos fenómenos sociales. Sin sostener que la explicación a través del concepto económico-social de clase es la única, no se ve por qué no pueda explorarse esta tesis hasta donde de de sí, desgajándola de adherencias que la práctica ha podido deposilar sobre la teoria.

Por lo que toca a otros aspectos sociologicos tampoco el marxismo aparece tratado con sobriedad cientifica. Se habla de una subordinación total de la persona a la colectividad, con lo cual se niegan los principios de una vida social y politica conforme con la dignidad humana. Como interpretación teórica del marxismo la afirmación es equivocada precisamente por lo exagerado o absolutizado; como constatación de algunos casos históricos puede que sea acerta$\mathrm{da}$, pero esa constatación puede muy bien extenderse a regimenes que se dicen liberales y democráticos en la historia de América Latina, sin que esto haya ocasionado quejas muy oficiales del magisterio eclesiástico. Por otro lado, no conviene olvidar fácilmente la prioridad del bien común sobre el bien individual tan lúcidamente sostenida por Santo Tomás para compensar ciertos entusiasmos individualistas o personalistas de última hora. ${ }^{20}$

Por lo que toca a aspectos éticos y sobre todo a la concepción ética fundamental tambièn la distorsión es importante. Se llega a decir que el carácter transcendente de la distinción entre el bien y el mal queda negado, aunque se reconoce que sólo implícitamente, en la óptica de la lucha de clases. Se habla también de un amoralismo politico. Si por amoralismo politico se entiende la habitual falta de moral no sólo de los políticos sino de las politicas que se siguen en nuestros tiempos como en los pasados, no hay mucho que puntualizar. Pero si por amoralismo politico se entiende la negación teórica de que el ejercicio de la política no debe ir dirigido por ningún principio moral y, en el caso del marxismo, por el cese de la explotación capitalista y la búsqueda más o menos ulópica de una sociedad sin clases, entonces esa acusación al marxismo no es la más apropiada. Como no lo es que se desdibuje la distinción objetiva entre el bien y el mal, por más que sea discutible el modo de encontrar esa distinción y los modos de concretarla.

En conclusión, no sería exagerado decir que hay aquí una caricaturización del marxismo, que ningún marxista ilustrado mantendria hoy. Lo cual no quiere decir que no se apunte con ello a desfiguraciones del marxismo en las cuales no sólo se ha cajdo y se cae, sino que es fácil ir a parar en ellas, si se simplifica y se mitifica el marxismo. En este sentido puede ser muy conveniente para amigos y detractores del marxismo un buen esfuerzo de desmitificación, que supone un constante repensar criticamente el valor 'científico' de los elementos fundamentales del análisis marxista. ${ }^{21}$

\subsubsection{Los influjos del marxismo sobre la teología de la liberación}

La Instrucción, como otros escritos eclesiásticos, parecen suponer que en el análisis marxista hay algunos elementos aceptables en sí mismos, pero que están tan estrechamente ligados a otros inaceptables que es dificil y casi impo- 
sible su separacion, por lo cual aquellos deben ser abandonados para no caer en estos: "La disociación de los elementos heterogéneos que componen esta amalgama epistemológicamente híbrida llega a ser imposible, de tal modo que creyendo aceptar solamente lo que se presenta como un análisis, resulta obligado aceptar al mismo tiempo la ideología" (VII, 6). En este mismo sentido se cita la frase de Pablo VI, sin duda mucho más matizada como corresponde a tal Papa, "sería ilusorio y peligroso llegar a olvidar el intimo vínculo que los une radicalmente, aceptar los elementos del análisis marxista sin reconocer sus relaciones con la ideologia, entrar en la práctica de la lucha de clases y de su interpretación marxista dejando de percibir el tipo de sociedad totalitaria a la cual conduce este proceso. "20 Pero no se cita la sagaz y cristiana observación de Juan XXIII: "Es también completamente necesario distinguir entre las teorías filosóficas falsas sobre la naturaleza, el origen, el fin del mundo y del hombre y las corrientes de carácter economico y social, cultural o político, aunque tales corrientes tengan su origen e impulso en tales teorias filosóficas. Porque una doctrina, cuando ha sido elaborada y definida, ya no cambia. Por el contrario, las corrientes referidas, al desenvolverse en medio de condiciones mudables, se hallan sujetas por fuerza a una continua mudanza. Por lo demás, ¿quién puede negar que, en la medida en que tales corrientes se ajusten a los dictados de la recta razón y reflejen fielmente las justas aspiraciones del hombre, puedan tener elementos moralmente positivos dignos de aprobación?"'23

Son tres posiciones distintas. La Instrucción, a pesar de que habla de elementos heterogéneos y de amalgama epistemológicamente hibrida, juzga, sin embargo, que es imposible esa separación de lo heterogéneo y de lo híbrido. Pablo VI afirma que seria ilusorio y peligroso no percatarse del vinculo existente entre elementos buenos o neutros y elementos no aceptables; de ahi se concluiria que recomienda cautela en la utilización del análisis marxista, al menos de algunas de sus partes. Juan XXIII cree, en cambio, que hay separación entre la doctrina y el análisis y que éste, aun siendo en un primer momento inaceptable, puede ir cambiando y aun cambiará inexorablemente por presión de las circunstancias, lo cual es evidente que ha ocurrido en la historia del marxismo tanto teórico como práctico.

Sería claro que si el marxismo es lo que dice la lnstrucción y si en él son inseparables los errores señalados de otros aspectos parcialmente positivos, debería abandonarse todo uso del mismo. Pero las dos afirmaciones no son en modo alguno ciertas. Es más bien un problema que no se puede resolver $a$ priori, sino que en cada caso hay que determinar si se ha caldo en errores no conciliables con la fe. Para la Instrucción este sería el caso de la teología de la liberación que critica.

En efecto, la Instrucción afirma y asegura que a) la impaciencia y una voluntad de eficacia han conducido a refugiarse en el análisis marxista (VII, I); b) la utilización de un método de aproximación a la realidad debe estar precedido de un examen de naturaleza crítica, cosa que no ha hecho más de una teologia de la liberación (VII, 4); c) no es raro que sean los aspectos ideologicos del marxismo y no los 'científicos' los que predominan en los préstamos 
que "muchos (el subrayado no está en el texto) de los "teólogos de la liberación' toman de los autores marxistas" (VII, 6); d) querer integrar en la teología un análisis cuyos criterios interpretativos dependen de una concepción atea - negado esto por Juan XXIII - y de una concepción materialista, es encerrarse en ruinosas contradicciones (VII, 9); e) la aplicación a la realidad económica, social y política de hoy de esquemas de interpretación tomados del pensamiento marxista pueden presentar a primera vista alguna verosimilitud pero, al hacer abstraccion de factores esenciales especificos, impiden de hecho un análisis verdaderamente riguroso de las causas de la miseria, y mantienen confusiones (VII, 11); I) se pasa con facilidad de las hipótesis a la concepcion totalizante que es propia del pensamiento de Marx (VII, 13).

Hasta aqui lo que pudiéramos considerar como observaciones de tipo metodologico, aunque ellas mismas son de graves consecuencias para la interpretación y la realización del mensaje evangélico. Si de ese estrato pasamos a la objeción de fondo, parecerá que ella consiste en que la teología de la liberación se ha apropiado de lo que sería el corazón del análisis marxista: la lucha de clases, una lucha de clases eso si inseparable de los errores más graves del marxismo. Como éste es uno de los puntos fundamentales de la crítica no estará de más recordar lo que Marx escribia a Weydemeyer el 5 de marzo de 1852, "Por lo que a mi se refiere, no me cabe el mérito de haber descubierto la existencia de las clases en la sociedad moderna ni la lucha entre ellas. Mucho antes que yo, algunos historiadores burgueses habian expuesto ya el desarrollo histórico de esta lucha de clases y algunos economistas burgueses la anatomia economica de éstas. Lo que yo he aportado de nuevo ha sido demostrar: 1) que la existencia de las clases solo va unida a determinadas fases históricas del desarrollo de la producción; 2) que la lucha de clases conduce necesariamente a la dictadura del proletariado; c) que esta misma dictadura no es de por sl más que el tránsito hacia la abolición de rodas las clases y hacia una sociedad sin clases...."24 Sin discutir más el texto ya de por si elocuente para dilucidar la separabilidad de la lucha de clases de la lucha de clases marxista y aun la lucha de clases marxista de otros elementos de la ideologia marxista, pasemos a ver como ve la Instruccion los perniciosos efectos de la utilizacion de la lucha de clases por parte de la teologia de la liberación para la fe. "Lo que estas 'teologías de la liberación' han acogido como un principio, no es el hecho de las estratificaciones sociales con las desigualdades e injusticias que se les agregan, sino la teoria de la lucha de clases como ley estructural fundamental de la historia..." (IX, 2).

Desde esta ley estructural se sacan varias consecuencias fatales: a) la lucha de clases asi entendida divide a la Iglesia y en función de ella hay que juzgar las realidades eclesiales (IX, 2); b) casi todos los errores dogmáticos que se apuntaron en 2.1. provienen de haber aceptado que la lucha de clases es la ley fundamental y el motor de la historia: identificación del Reino de Dios con la liberación humana, autorredención del hombre, identificación de Dios con la historia, politización radical de las afirmaciones de la fe y de los juicios teológicos, negación de la realidad teologal de la fe, esperanza y caridad, etc.; c) en especial la Iglesia de los pobres y la Iglesia del pueblo "significa asi una Iglesia 
de clase, que ha tomado conciencia de las necesidades de la lucha revolucionaria como etapa hacia la liberación y que celebra esta liberación en su liturgia" $(\mathrm{IX}, 11) ;$ d) la teología misma es entendida en clave de clase de modo que la que sirve a la clase opresora es sin más desautorizada y la que sirve al proletariado es sin más mantenida como verdadera $(X, 1)$, de modo que "los criterios teológicos de verdad se encuentran asi relativizados y subordinados a los imperativos de la lucha de clases. En esta perspectiva, se substituye la orrodoxia como recta regla de $\hat{\text { ee, }}$ por la idea de ortopraxis como criterio de verdad" (IX, 3); e) la doctrina social de la Iglesia es rechazada con desdén por ser propia de las clases medias que no tienen destino histórico; (IX, 4); f) se llega a una relectura esencialmente politica de la Escritura (IX, 5); f) se cae en un mesianismo temporal (IX, 6), incluso se cae en los más graves errores cristológicos (IX, 7 12) ya recogidos anteriormente en $2.1 . ; \mathrm{g}$ ) "la unidad, la reconciliación, la comunión en el amor ya no se conciben como don que recibimos de Cristo. La clase histórica de los pobres es la que constituye la unidad, a través de su lucha. La lucha de clases es el camino para esta unidad. La Eucaristia llega a ser asi Eucaristia de clase. Al mismo tiempo se niega la fuerza triunfante del amor de Dios que se nos ha dado"' $(X, 16)$.

Aunque algunos de estos errores son atribuidos también a la utilización de una hermenéutica racionalista, su causa principal está en el influjo del marxismo y, más en particular, de tomar como eje central de toda interpretación la lucha de clases. Sin embargo, resulta del todo problemático aceptar la conexión de los errores imputados, sobre todo los más estrictamente dogmáticos, con una interpretación marxista de la lucha de clases. Las cosas están de tal modo extremadas en la Instrucción que su fiabilidad en éste como en otros puntos es desde una perspectiva racional muy escasa. Mucho se afirma, pero poco se prueba. Y si el método de afirmar es correcto cuando se quiere señalar qué es lo compatible con la fe y qué no lo es, no lo es a la hora de referirse a la concatenación lógica de puntos que le competen a un análisis racional. Si en vez de seguir este procedimiento la Instrucción se hubiera contentado con descubrir con la mayor concreción posible en qué autores se dan los errores teológicos impulados, cómo en ellos la fuente determinante de su discurso es la marxista y cómo en particular el principio de la lucha de clases opera a la hora de dar un sentido determinado a tales o cuales afirmaciones teológicas, hubiera hecho una labor más científica y, en definitiva, más útil. Lo que de ella se puede sacar en este punto es, tal como está, el tener cuidado en no caer en lo que ella señala como peligroso, no porque ya se ha caido, sino porque hay la posibilidad de que eso suceda, lo cual ciertamente seria pernicioso. Esto nos lieva al siguiente apartado.

\section{3. ¿Hay teologías de la liberación como las descritas en la Instrucción?}

Según el sentido general y la letra particular de la Instrucción hay, sobre todo, en América Latina teologias de la liberación que caen en todos o en buena parte de los graves errores que se denuncian. La Instrucción previene de peligros en los cuales se puede caer y avisa de errores en los cuales se ha caido. Discutir este punto es importante no sólo para calibrar el acierto de la Instrucción, sino también para aclarar al pueblo fiel que tal vez estima como condena- 
das obras y autores que no lo están y que más bien deberían ser leidos y alabados por cuanto son los cultivadores creativos de lo que en el apartado primero decíamos ser una gran necesidad para la Iglesia.

La Instrucción se refiere a "el movimiento teológico y pastoral conocido con el nombre de 'teología de la liberación"' (III, 2), que se da sobre todo en América Latina, pero tambièn en otras regiones del tercer mundo y aun en ciertos ambientes de los paises industrializados. Se trata de un "movimiento de ideas" que encubre posiciones teologicas diversas con fronteras doctrinales mal definidas" (III, 3). Entre estas teologias de la liberación hay algunas correctas, que responden desde un punto de vista totalmente cristiano a las aspiraciones de los hombres y de los pueblos hacia su liberación e incluso lodas ellas mantienen un núcleo inicial sano: "la expresión 'teologia de la liberación' designa en primer lugar una preocupación privilegiada, generadora del compromiso por la justicia, proyectada sobre los pobres y las víctimas de la opresion" $(I I I, 3)$. Pero tras ese punto de arranque vienen las divergencias y lo que la InsIrucción condena son las teologias de la liberación "que recurren, de modo insuficientemente critico, a conceptos tomados de diversas corrientes del pensamiento marxista" (Introducción). Estas tienen de bueno la opción preferencial por los pobres a la cual la lglesia se compromete con todas sus fuerzas en Medellín y Puebla y aun en documentos de mayor alcance universal, pero tienen de malo el reducir el Evangelio de la salvación a un evangelio puramente terrestre (VI, 5). Explícitamente se dice que "el presente documento sólo tratará de las producciones de la corriente de pensamiento que, bajo el nombre de 'teologia de la liberacion' proponen una interpretación innovadora del contenido de la fe y de la existencia cristiana que se aparta gravemente de la fe de las lglesias, aún más, que constituye la negación práctica de la misma" (VI, 9). Con todo la Instrucción hace una salvedad sobre los puntos que condena: "las posiciones presentadas aqui se encuentran a veces tal cual en algunos escritos de los 'teólogos de la liberación'. En otros, proceden lógicamente de sus premisas" (IX, 1). Más aún matiza: "uno se encuentra pues adelante de un verdadero sistema, aun cuando algunos duden de seguir la lógica hasta el final" (ib.). Eventualmente se reconocen algunos méritos como una mayor preocupación por los pobres y también "haber valorado los grandes textos de los Profetas y del Evangelio sobre la defensa de los pobres" (IX, 10). Pero no es que se falle en tal o cual afirmación, sino en su totalidad, precisamente por su carácter global y totalizante; la teología de la liberación aquí cuestionada "debe ser criticada, no en tal o cual de sus afirmaciones, sino a nivel del punto de vista de clase que adopta a priori y que funciona en ella como un principio hermenéuticodeterminante" $(X, 2)$. Sin embargo, se mantiene que de momento se trata de una "llamada de atención conira las desviaciones de ciertas "teologias de la liberación"' (XI, l). Se recoge, sin embargo, un principio melodológico propio de estas teologias: "la experiencia de quienes trabajan directamente en la evangclización y promoción de los pobres y oprimidos es necesaria para la reflexión doctrinal y pastoral de la Iglesia. En este sentido, hay que decir que se tome conciencia de ciertos aspectos de verdad a partir de la praxis, si por ésta se enliende la práctica pastoral y una práctica social de inspiración evangélica" (XI, 
13). Quizá donde las ideas están más confusas no es en los propios teólogos acusados, sino en la asimilación de las mismas en forma simplificada por "grupos de base que carecen de preparación catequética y teológica" (XI, 15).

Todo este cúmulo de citas que siguen fundamentalmente el orden la Instrucción muestran lo difícil de precisar qué teólogos o qué obras son las que están en la mira y a quiénes se dirige esta llamada de atención. ¿Hay alguno que caiga en todo esto? ¿Se cae en ello incluso cuando no se quiere y cuando no se dice por el a priori imputado que da carácter sistemático y univocamente orientado a unas consecuencias inevitables? ¿Están tomadas de muchos autores, de los cuales unos dicen unas cosas y otros otras, de modo que lo formulado en la Instrucción es una construcción teórica, que no responde a ningún autor en particular, pero sí a un movimiento más o menos orientado por los mismos principios, aspiraciones y métodos? En particular, el uso del marxismo ies en la mayoria de ellos o en algunos de ellos tal como se describe en la Instrucción?

La falta de método científico en la Instrucción hace muy difícil el responder a estas cuestiones. Puede verse en la falta de citas comprobantes, a pesar de que se afirma en la Instrucción que algunos de los errores condenados se encuentran tal cual en los autores, una benevolencia paternal que trata de evitar. condenas apresuradas. No obstante, en la presentación que hizo del documento Monseñor Quarracino, recordémoslo, se dice que, aunque no se citan autores ni textos, "es obvio que ha sido redactada teniendo en cuenta unos y otros' "25. Y en el "Resumen del documento," que se repartio con el mismo se advierte que "no contiene ninguna cita directa sacada de obras importantes sobre la materia. Hacerlo seria dar a algunos, no explícitamente citados, el pretexto de decir que a ellos no les afecta el documento." 26

Sin embargo, podemos señalar a algunos autores que públicamente han sido advertidos por los mismos redactores o firmantes de la Instrucción. Estos son principalmente Gustavo Gutiérrez, Leonardo Boff y Jon Sobrino, aunque en el escrito de Ratzinger en 30 Giorni se citan también los nombres de Assman y Ellacuría. Atenderemos tan sólo a los tres primeros por la importancia de su obra teológica.

A Gustavo Gutiérrez se le imputaron 10 observaciones todas ellas centradas en el carácter determinante que tendría el marxismo en su teología, representada sobre todo en sus libros Teologia de la Liberación y la Fuerza histórica de los pobres. ${ }^{27}$ En esas observaciones encontramos lo fundamental de la Instrucción por lo que toca al efecto nefasto del marxismo sobre la teología de la liberación: a) bajo el pretexto del carácter 'científico' del marxismo, se admite la concepción marxista de la historia con el punto central de la lucha de clases: "tal es el principio determinante de su pensamiento; de aquí parte para reintepretar el mensaje cristiano;" b) "se procede a una amalgama entre el pobre de la Biblia y el explotado victima del sistema capitalista. Asi se llega a justificar el empeño revolucionario en favor de los pobres;" c) se leen ciertos textos escrituristicos capitales con un "significado restrictivamente politico;" d) "aunque no lo admita, cac en un mesianismo temporal que reduce el creci- 
miento del Reino al progreso de la "justicia' en la sociedad;" e) reduce el pecado al pecado social; ) la influencia del marxismo se nota en la concepción de la verdad y en la noción de teologia; se compromete la transcendencia de la revelación, se desvía el sentido de la formula 'Dios se hace historia' y se considera que la teología refleja los intereses de clase; $g$ ) el reino se edifica a través de las luchas de liberación, la unidad de la Iglesia se conquista a través de la lucha de clases y se pone en cuestión la reconciliación y la salvación ya dadas por Jesucristo; h) hay una falsa concepción del pobre y de la Iglesia de los pobres que introduce la lucha de clases dentro de la misma Iglesia y de la interpretacion de la Eucaristia; i) se acepta acriticamente la lucha de clases con lo que tiene de recursos a la violencia; $j$ ) "como meta se tiende a hacer del cristianismo un factor movilizador al servicio de la revolución;" por recurso al marxismo se puede pervertir la inspiración cristiana y el sentido de los pobres y de sus esperanzas.

A Leonardo Boff se le acusa melodológicamente de hacer poco uso de la doctrina de la Iglesia y del magisterio, de tener poca precisión teológica y se pone en duda si sus páginas están guiadas por principios de naturaleza ideológica de cierta inspiración neo-marxista. En cuanto al contenido, se le acusa de una interpretación relativizante de la Iglesia católica con severas críticas a su estructura actual, que no seria la querida por Jesús. Se le acusa también de proponer una explicación alternativa al dogmatismo de las verdades y a la comprensión doctrinal de la revelación, que a veces viola los derechos de los fieles; esta explicación llevaria también a una relativización de las formulas dogmáticas y de los criterios para establecerlas. Se le acusa también de desvirtuar el ejercicio del poder sagrado, tal como debe ser ejercitado en la Iglesia, al amparo del principio de que el eje organizador de una sociedad coincide con sus modos específicos de producción. ${ }^{28}$

Jon Sobrino es atacado en el articulo de Ratzinger ya citado.29 "Sobrino reemplaza fundamentalmente, por consiguiente, la fe por la 'fidelidad a la historia." ' Más aún en él "se produce aquella fusión entre Dios y la historia que hace posible a Sobrino, conservar con respecto a Jesús la formula de Calcedonia pero con un sentido totalmente alterado." La esperanza se interpreta como 'confianza en el futuro' y como trabajo para el futuro y con esto "se subordina nuevamente a la dominante de la historia de clases. El 'amor' consiste en la 'opción por los pobres', esto es, coincide con la lucha de clases. Según Sobrino el reino no debe comprenderse de modo espiritualista, ni universalista, ni en el sentido de la reserva escatológica abstracta; debe ser entendido en forma partidista y orientado hacia la praxis. "Quisiera mencionar también la interpretación impresionante, pero en definitiva espantosa, de la muerte y de la resurrección que hace J. Sobrino; establece, ante todo, en contra de las concepciones universalistas, que la resurrección es, en primer lugar, una esperanza para los crucificados..."

Esle breve recorrido por estos tres autores muestra a las claras a quiénes se pretende dirigir la Instrucción. Desde luego que no solo a ellos, pero sí a ellos de modo principal. Gran parte de los pensamientos contenidos en ella están casi literalmente recogidos en otros escritos dirigidos contra estos tres autores y 
la idea general, así como el método y el estilo, de la Instrucción demuestran la misma autoria y la misma intención en un caso y en otro.

Esta constatación nos lleva a un problema grave en donde está en juego la justicia y está también en juego el futuro de la teologia de la liberación y con ella, en alguna medida, el futuro de la Iglesia de los pobres y de los pobres mismos. ¿Dicen estos autores lo que la Instrucción atribuye a la teologia de la liberación? La respuesta no tiene dubitación posible: no. No desde un punto de vista subjetivo y no desde un punto de vista objetivo. Desde un punto de vista subjetivo porque consta que ellos no quieren decir eso que se les atribuye; desde un punto de vista objetivo porque sus textos tomados en su conjunto no dicen lo que se les fuerza a decir, antes al conlrario dicen cosas muy distintas y aun opuestas. Ėn esas transcripciones ni se hace justicia a todo lo que esos autores dicen - cosa tal vez no pretendida por la Instruccion-, ni se tiene en cuenta lo mejor que dicen - aunque a veces en relaciones personales se reconocen sus buenas intenciones y aun algunos de sus logros-, ni siquiera se interpreta adecuadamente lo poco que de ellos se recoge. Hay en general un mal conocimiento de lo que se critica y condena y hay, además, una mala interpretación de eso poco que se conoce.

A los obispos del Perú, a su conferencia episcopal, a pesar de la presión a la que se han visto sometidos les ha sido imposible poder coincidir con las acusaciones que se le habian hecho a Gustavo Gutiérrez; ciertamente algunos de los obispos pensaban que eran acertadas, pero no se pudo llegar a un consenso, precisamente porque quienes mejor conocian su obra y su persona no podian estar de acuerdo con tal caricatura. No se han tornado en consideración las muchas veces que Gutiérrez dice lo contrario de lo que se le atribuye, amparado su crítico en tal o cual frase suelta, incluso en tal o cual frase menos afortunada en su formulación. No se ha tomado en cuenta el enorme esfuerzo hecho por Gutiérrez por abrir la liberación terrena a toda su dimension inmanente que no se reduce a algo exclusivamente politico y también a toda su dimensión transcendente, llena de gracia y de experiencia espiritual, como lo demuestra hasta la saciedad su importante libro sobre espiritualidad Beber en su propio pozo. ${ }^{30}$ Más aún, el dificil problema melodologico del uso de las ciencias sociales en el quehacer teológico, que la propia Instrucción considera posilivo en algún grado, ha sido tratado explícilamente por Gutiérrez últimamenre, pero recogiendo lo que ha sido su práctica teórica desde hace muchos años. ${ }^{31}$ Entre otros puntos importantes que muestran el lugar derivado que tienen las ciencias sociales en la reflexión teológica y dentro de las ciencias sociales el lugar reducido que compete a algunos elementos del marxismo, no sólo niega que el marxismo sea la ideologia que domina su quehacer teológico y menos su fe, sino que a firma taxalivamente de la lucha de clases como motor o ley de la historia, en primer lugar, que no es tan esencial el marxismo como se piensa, pero sobre todo que a su pensamiento eso no le atañe: "lo que nos importa aqui es decir que no es eso lo que pensamos y que por consiguiente jamás hemos empleado estas expresiones." 32

El ataque contra Leonardo Boff es más suave y no está recogido muy expresamente en la Instrucción. Pareceria que tras su diálogo con Ratzinger al- 
gunos de los principales malentendidos estuvieran en trance de desaparecer. Notorio es el amparo que le han ofrecido constantemente no soblo los miembros de su orden religiosa, sino tambièn cardenales de tanto peso y tan conocedores de su persona y de su obra como Arns y Lorscheider. Es conocida su confesion en la respuesta escrita que dio a la Sagrada Congregación para la Doctrina de la Fe: "prefiero la Iglesia a mi teología, pues la Iglesia permanece mientras que las teologías pasan; además la Iglesia es objeto de fe (sacramento de salvación) y las teologias son producciones culturales humanas, objeto de estudio y de crítica, más no de fe." Asegura que las frases citadas por Ratzinger de uno de sus libros son Irases sacadas de aqui y de alli fuera de su contexto; leyendo esos contextos se apreciaría que su posición es mucho más equilibrada de lo que se le atribuye en la acusación.

Asimismo el ataque a Jon Sobrino es todo un conjunto de desfiguraciones. Cualquiera que conozca medianamente bien no ya la biografía de Sobrino, sino su obra escrita sabe de sobra que la presencia del marxismo es en ambas absolutamente accidental y de ningún modo configuradora de su pensamiento ni de su acción. La caricalura de su pensamiento que se hace en el artículo de Ratzinger ha sido desautorizada por el ponderado estudio de Juan Alfaro, conocido teólogo romano que si se ha tomado el trabajo de estudiar teológicamente la producción latinoamericana y en particular la abundante bibliografia de Jon Sobrino, de quien ya se han hecho diversas tesis doctorales, que ponen en claro algunos aspectos de su pensamiento. ${ }^{33}$

Tal vez pueda afirmarse que la presencia del análisis marxista es más fuerte en otros autores, asociados a la teología de la liberación y aun que los teólogos de la liberacion en general no son en ningún caso anti-marxistas y que incluso se sirven de elementos marxistas. Es una cuestión que debe comprobarse en cada caso. Sin embargo, y hablando en general, puede decirse que el marxismo se hace más presente a finales del sesenta y principio del setenta y que desde entonces va disminuyendo el peso que desempeña en la producción teórica y aun en los análisis sociales que tienen que ver con la teología y la praxis pastoral. Las muy ponderadas reflexiones de Clodovis Boff sobre la presencia del materialismo histórico como caso concreto de mediación socio-analítica son muy dignas de tenerse en cuenta, pues es el autor que más ha reflexionado sobre aspectos metodológicos de la teologia de la liberación: "el marxismo merecerá la credibilidad de los aconlecimienlos probados que sea capaz de producir a titulo de teoria cientifica. De este modo, el marxismo no goza de ningún privilegio a priori... 34 "Vemos entonces que el marxismo no puede servir como mediación socio-analítica más que en calidad de reoria cienrificu (y sólo en la medida en que es cientifica) y no como una Weltanschauung omniexplicativa. En cuanto a ésta, la teología no puede dejarse medir por su pauta ni resignarse al lugar que le reserva (en la superestructura), ya que entonces la teologia dejaria de ser teología..."3s

Hoy en lodo este problema dos cuestiones distintas. Una, la de discutir si el marxismo es conciliable en alguna de sus partes, incluso principales, con la fe cristiana. Varios de los teólogos de la liberación propenden a decir que si, aun admitiendo la complejidad del problema que obliga a distinciones precisas 
y a cautelas pastorales. Otra, la de medir el peso del marxismo en los propios escritos teológicos; en este segundo caso hay diferencias notables, pero en general se trata de algo subordinado y no subordinante. Pero lo que no se puede aceptar es que esas teologías contengan los errores dogmáticos que se le atribuyen y que esos presuntos errores estèn ocasionados por la aceptación previa del marxismo como ciencia. Los teólogos de la liberación saben de la prioridad de la fe, de la revelación y del magisterio y tienen también sus criterios epistemologicos que no les permiten caer en la ingenuidad de considerar univocamente como científico al marxismo. Lo que sí estiman, con Juan XXIII, que todo lo que en él haya de aprovechable, aunque sea como hipótesis provisional más heurística que interpretativa, no sólo puede ser aprovechado, sino que debe serlo. Tantos o más peligrosos han tenido sistemas 'científicos' como el aristotelismo, el kantismo, el hegelianismo, el freudismo, etc., y sin embargo, los teólogos y filosofos cristianos no han tenido temor de echar mano de sus logros. La permision del mal para que se den bienes mayores es, además, un principio clásico de la teodicea agustiniana.

Si esto es así, queda abierto un gran interrogante. ¿Qué es lo que ha hecho ver a los censores romanos lo que no hay en los escritos teológicos que critican? ¿Hay en esos escritos y en el efecto de esos escritos algo que justifique su preocupación?

Una explicación parcial, pero insuficiente está en el escaso y mal conocimiento que tienen de aquello que se juzga, al menos tal como aparece en los escritos dedicados al tema. La lalta de citas y de referencias explicilas, la atención a algunas frases sueltas sin análisis de los contexlos, el olvido de una gran parte de la producción de los autores criticados, es ya una prueba de esto. Igualmente cabe referirse a la falta de conocimiento de las personas y de las situaciones concretas a las que se refieren en su trabajo teológico y pastoral. Pero para buscar una explicación más a fondo tal vez sea preciso apelar a un prejuicio con algún fundamento real, que imposibilita una comprensión adecuada y un juicio balanceado. Ciertos teólogos romanos, salvada su pureza de intención, han sido capaces de ver en determinados escritos errores graves con una posible intepretación de lo que en ellos se dice, incluso apelando al subconsciente de los autores o a una lógica que no siguen, pero que llevaria forzosamente a esa interpretación. En esto coinciden con los marxistas que, ajenos a la fe cristiana, ven en los teólogos de la liberación o en algunos de sus escritos algunos aspectos más o menos comunes; desde su no-fe hacen una lcclura parcial de esos escritos. Extraña coincidencia que demuestra una parcialidad de signo opuesto. Marxistas y anti-marxistas estarian haciendo una lectura equivocada, por parcial, de los textos principales de la teologia de la liberación. Ambos grupos van predominantemente regidos por preocupaciones prácticas: el evitar que la propia clientela se pase a la contraria; para unos la teologia de la liberación podría suponer un nuevo desafio a la no-fe de los marxistas, mientras que para otros podría suponer una invitación a una lectura marxista de la fe cristiana.

Alguna parte de la jerarquia católica vería con preocupación, surgida a veces de la constatación de hechos reales, que la teologia de la libcración 
pueda suscitar en gran parte del pueblo creyente una tendencia a la politizacion y manxistización de su fe, que llevaría lentamente a la pérdida o debilitamiento de la misma, a la constitución de una Iglesia popular separada o al menos a la introducción de la lucha de clases dentro de la misma Iglesia, al recurso a la violencia armada y finalmente al establecimiento de estados totalitarios marxistas. Estos males de desigual importancia desde el punto de vista de la fe y de la existencia cristiana, es claro que deben ser evitados. Pero intentar evitarlos con la condena de los mejores teólogos de la liberación de cuya fidelidad a Cristo y a la Iglesia no puede dudarse, sería un gran error. Los teólogos de la liberación llevan entre manos una tarea de singular importancia para América Latina, para el tercer mundo y, lo que es más importante, para la vigencia y la vivencia de la fe cristiana. Impedirsela sería un gran error, porque la tarea seguiria adelante en manos menos seguras y dóciles que las de ellos. Los teólogos de la liberación no son infalibles, pero son confiables $y$ han demostrado estar abiertos al diálogo, cosa que se niega inconsideradamente en la Instrucción, siempre que el diálogo se desarrolle cristianamente. Si a la disposición demostrada por ellos se junta un mayor esfuerzo por parte de la jerarquia y del magisterio, podrán evitarse errores futuros y podrán disminuirse riesgos. Las cosas oscuras pueden aclararse más y las formulaciones menos felices pueden corregirse. En ello están los mejores teólogos de la liberación, que han sido los mejores críticos y a veces los más duros de sus propias posiciones.

\section{Un paso adelante en la teología de la liberación}

A pesar de las apariencias, la Instrucción no debe verse como un paso negativo o un freno a la teologia de la liberación. No ha sido vista así por los propios teólogos, cuya respuesta ha sido en general positiva, mostrando una vez más su docilidad cristiana. ${ }^{36}$ El que se haya reconocido no sólo la validez, sino la necesidad de la teología de la liberación, como algo que falta en la Iglesia y que la Iglesia lo requiere; el que se haya aceptado que algunas de las teologias de la liberacion no sólo han suscitado problemas importantes, sino que han tenido ya logros apreciables; el que se sentalen con claridad peligros que deben evitarse muy cuidadosamente, cuidado que tal vez no se ha tenido en todas y cada una de las ocasiones; el que se advierta sobre el efecto que los escritos teológicos pucden producir sobre un pueblo fiel sometido a tensiones revolucionarias y cortejado por movimientos manxistas-leninistas, constituyen un conjunto de aspectos muy valiosos que animan a no dejar la tarea, sino a continuarla con mayor esfuerzo y diligencia.

Para hacerlo y según lo indicado por la misma Instrucción debieran tenerse positivamente presentes algunos puntos principales.

Ante todo, el punto de partida. Hay que devolver a los pobres y a los oprimidos el pucsto preferencial que les corresponde no sólo en la Iglesia, por la voluntad expresa de Cristo, sino también en la reflexión teológica; aquellos que son' los "hermanos desheredados, oprimidos o perseguidos" (Introducción). Sin exclusivismos, pero con clara preferencia. Esta opción preferencial por los pobres, que no es excluyente, pero que debe ser real y efectivamente preferente se reitera con energia en la Instrucción tanto positivamente como 
negativamente al condenar a quienes amparados en las advertencias a la teologia de la liberación ejercen en la práctica una opción preferencial por los ricos o al menos no practican lo que deben en lavor de los pobres.

A estos pobres hay que anunciarles muy expresa y centralmente la libertad que viene de la liberación. Una liberación que es sobre todo liberación del pecado, de todo pecado y no sólo del pecado interior, pero que tambièn es liberación material, socio-histórica, que atiende a todo el hombre y a todos los hombres que se vean privados de su libertad o desprovistos de lo que es necesario para vivir dignamente como lijos de Dios. La libertad conquistada y ofrecida por Crisıo debe traducirse hisı́ricamente y debe realizarse ya, aunque lodavia no se logre de forma perlecta. Podria decirse que si no se realiza ya de alguna manera esa libertad y esa liberación, vana es la mucrte y la resurrección de Cristo. Queda mucho por hacer en el pensamiento y en la práctica personal de la Iglesia por lo que toca a esta libertad y liberación vistas preferencialmente descle los pobres y referidas principalmente a ellos y con ellos al resto de los hombres. Esto lo debe hacer una teologia de la liberación auténticamente cristiana, que en parte ya ha sido puesta en marcha.

Para realizar esta tarea tanto teórica como práctica "se debe ejercer el discernimiento de las expresiones, teóricas y prácticas, de esta aspiración" (1I, 2). Hay que descubrir "el sentido de la aspiración profunda de los nuelılos a la justicia," pero también hay que examinar "con un discernimiento crilico, las expresiones teóricas y prácticas, que son datos de esta aspiración" (II, 4).

Particular importancia cobra la relectura de la Escritura desde esta aspiración de los pueblos y de los hombres a una total liberación. Como método para ello "no es posible olvidar ni un solo instante las situaciones de miseria dramálica de donde brota la interpelación así lanzada a los leólogos (IV, I). La Escrilura tanto en el Antiguo como en el Nuevo Testamento está llena de profundos aportes a este terna central de la liberacion. Todos ellos deben tenerse en cuenta sin quedarse parcialmente en uno o el otro de los testamentos.

También resulıa especialmente útil a la teologia de la liberación y a la praxis indisolublemente ligada con ella el recurso a las ciencias sociales: "es evidente que el conocimiento científico de la situación y de los posibles caminos de transformación social es el presupuesto para una acción capaz de conseguir los fines que se han fijado. En ello hay una señal de la seriedad del compromiso" (VII, 3). Precisamente por su importancia la utilización de un método de aproximación a la realidad debe estar precedido "de un examen crítico de naturaleza epistemológica"' (VII, 4). Conviene atender a la pluralidad de métodos que se dan en las ciencias sociales y no cerrarse en uno solo. En ese examen crítico hay que tener en cuenta la luz de la fe: "la utilización por la teologia de aportes filosoficos o de las ciencias humanas tiene un valor "instrumental" y debe ser objeto de un discernimiento crítico de naturaleza teologica" (VII, 10). Al utilizar un determinado análisis debe además observarse una "total docilidad respecto a la realidad que se describe. Por esto una conciencia crítica debe acompañar el uso de la hipótesis de trabajo que se adoptan" (VII, 13).

La praxis misma desde la que se reflexiona y/o sobre la que se reflexiona 
debe tenerse muy en cuenta: "una sana melodología teológica tiene en cuenta sin duda la praxis de la lelesia en donde encuentra uno de sus fundamentos, en cuanto que deriva de la le y es su expresión vivida" $(X, 3)$, donde se puntualiza alguna de las formas en que esıo sc lleva a cabo en la teologia de la liberación, pero donde por otra parte se apunta hacia un camino no muy recorrido por los teólogos usuales.

Entre estas ciencias sociales hay que lener especial cuidado con el uso del marxismo. Hemos hecho anteriormente dos conslalaciones: que el marxismo estigmati/ado por la losurucion es "un" marxismo muy delormado y qui cl marxismo empleado por algunos teólogos de la liberación no es, ell primer lugar, ese marxismo deformado y no es, en segundo lugar, el elemento que determina en última instancia cl aportc especificamente cristiano. Consiguichtemente, ni siquiera después de la Instructión debe uno sentirse obligado a abandonar el recurso al marxismo en lo que pueda lener de cientifico o simplementc razonablemente útil tanto en sus plantcamicnus téóricos como en sus propuestas prácticas; ciertamente no deberá ser absolutizado ni en su carácter científico ni, menos, en su carácter de cosmovisión última; más aún deberá ser utilizado con cautela, sobre lodo por el mal uso que de él puedan hacer personas sin formación que no conocen sulilczas crilicas. Pero, por olro lado, no podrá ser abandonado en lo que licne de aporte posilivo tanto en sus aspectos críticos como en sus propuesıas. Lo que sí habrá que tener en cuenta es que los posibles males que comporte no sean mayores que los males quc evite o los bienes que aporte. Hay o puede haber un interés por parte de los marxistas de servirse de los esfuerzos de la teología de la liberación para robustecer sus posiciones ideologicas y politicas; esto no lo hacen sin riesgo porque la leologia de la liberación pone en crisis algunos puntos importantes del marxismo. Tal subordinación debe evitarse porque no es lo mismo servir a la liberación inlegral de las masas populares que servir a determinadas organizaciones o po deres políticos que dicen estar al servicio de ellas desde una perspectiva marxista. Pero no por eso deben romperse los puentes. Una utilización ponderada y crítica, renovadamente critica, del marxismo es todavia por varias razones coyunturales una necesidad en sectores importantes del pensar y del hacer en América Latina. Pocos podrán negar que el marxismo tebrica y práclicumente es un instrumento útil para combatir la opresión ideológica y económica que el capitalismo induce de modo salvaje sobre una gran parte de la población mundial. Aunque pueda discutirse si lleva o no a otras formas de opresión siempre y en todo lugar, parece indiscutible que ayuda a quitarse de encima la opresion capitalista. Esta puede parecer liviana en Europa o en Estados Unidos, mientras aquella parece insoportable en Polonia o en Albania; pero en la mayor parte de América Latina la opresión capitalista, lejos de ser liviana, es en términos reales mucho más gravosa de lo que puede ser su contraria en la Unión Soviélica o en Polonia. Tener esto en cuenta es importante para no medir con distinta balanza a las ideologías y a los sistemas. Los peligros de ingenuidad o de olvido no están sólo en uno de los lados. Por otra parte, es necesario pasar del moralismo político a una efectiva política moral.

En este esfuerzo es obvio que ha de tenerse muy gran cuidado el presentar 
integralmente el misterio cristiano y para ello habrá que señalar algunos aspectos que la Instrucción recoge: "transcendencia y graluidad de la liberación en Jesucristo, verdadero Dios y verdadero hombre, sobesania de su gracia, verdadera naturaleza de los medios de salvación, y en particular de la Iglesia y de los sacramentos. Se recordará la verdadera significación de la ética para la cual la distinción entre el bien y el mal no podrá ser relativizada, el sentido auténlico del pecado, la necesidad de la conversión y la universalidad de la ley del amor fraterno. Se pondrá en guardia contra una politización de la existencia que, desconociendo a un tiempo la especilicidad del reino de Dios y la transcendencia de la persona, conduce a sacralizar la política y a captar la religiosidad del pueblo en beneficio de empresas revolucionarias" (XI, 17). Derivadamente se deberá tener en cuenta la enseñanza social de la Iglesia, en la que sin duda se predican valores y se incita a buscar soluciones, que son de gran utilidad, aunque sin desconocer la permanente evolución que esa enseñanza ha tenido y que por su propia naturaleza ha de tener. En general, será importante tener muy en cuenta los aportes de la tradición y del magisterio dentro de las normas que competen al trabajo teológico, al cual tanto deben una y otro.

Todo ello requiere fundamentarse en la verdad: la verdad sobre Jesucristo el Salvador, la verdad sobre la Iglesia, la verdad sobre el hombre y sobre su dignidad, como recordaba Juan Pablo lI en Puebla (XI, S). Pero lo que ya sabemos sobre Jesucristo, sobre la Iglesia y sobre el hombre, aun en lo que liene de relativa conformidad con lo que realmente son Jesucristo, la Iglesia y el hombre, están muy lejos de adecuarse con lo que son en realidad. Hay todavía mucho que decir y mucho que buscar. La teología de la liberación ha logrado en los tres campos avances notorios, pero tiene todavía ante sí el gran desafio de seguir avanzando no sólo en mostrar más adecuadamente a los demás hombres lo que ya se sabe y se ha recibido, sino en aumentar el saber recibido, en acrecentar la comprensión y la explicitación del deposito inagotable de la fe, cuyas posibilidades están dadas ya pero cuya actualización está muy lejos de haber quedado agotada. Sería una petulancia creer que ya sabemos no sólo lo que es Dios, la Iglesia y el hombre en sí mismos (quoad se), sino creer que ya sabemos lo que nosotros mismos, la humanidad a lo largo de su historia, puede llegar a saber (quoad nos). Eso que no sabemos no es deducible sin más de lo que ya sabemos y si lo llegamos a saber, puede revertir sobre lo que ya sabíamos, que tal vez no quede abrogado, pero sí, superado; el constante avance de los concilios en materia cristológica es prueba manifiesta de ello. La teologla de la liberación entiende que desde la opción preferencial por los pobres, con su doble componente teórica y práctica puede acrecentarse de forma importante la verdad sobre Dios, sobre la Iglesia, sobre el hombre. Pareceria que la Instrucción está de acuerdo en este punto, aunque también está preocupada por la gravedad de la tarea y de su propia dificultad.

Con estos lineamientos la teologia de la liberación debe seguir adelante. Es una necesidad para la Iglesia y es especialmente una necesidad para los pobres a los que se reconoce un lugar preferencial en el corazón de Dios y en el corazón de la Iglesia. La Instrucción puede favorecer esta tarea al animar su prosecución, al advertir de los peligros y al posibilitar un diálogo sincero y res- 
petuoso. Los peligros de los que advierte han sido superados autocriticamente por la propia teologia de la liberación. Por eso tal vez puede decirse que la Instrucción ha llegado con unos diez años de retraso, lo cual tal vez explica el modo distinto como ven el asunto los que se han detenido en la fase primera de la teologia de la liberación y los que ya están en la fase actual, que, lejos de repetir la primera, la completan y la hacen avanzar. Quizá algunos de aquellos escritos primeros, transmitidos de forma poco rigurosa, pueden seguir teniendo algún influjo pernicioso en determinados grupos que por diversas razones han quedado descolgados del movimiento de la teología de la liberación. A esto parece referirse la Instruccion cuando advierte que "la tesis de las 'teologias de la liberación' son ampliamente difundidas, bajo una forma todavia simplificada, en sesiones de formación o en grupos de base que carecen de preparación catequética y teológica..." (XI, 15). Ciertamente no tienen el mismo estatuto epistemológico las cosas que dicen los teólogos en sus libros que las dichas en la predicación o las expresadas por las comunidades de base. Aunque la Instrucción hace bien al considerar la teología de la liberación como un movimiento complejo en el que no sólo intervienen teoblogos profesionales sino también los creyentes sencillos que reflexionan sobre su fe y la iluminan, no debería a la hora de la crítica tomar en el mismo rigor las expresiones de unos y de otros. Se tiene la impresión de que se quiere cargar a los téblogos con las consecuencias que han sacado de sus escritos todos y cada uno de los lectores y también que se quiere cargar sobre los creyentes y su fe, algunas formulaciones que de ellas hacen ellos mismos o algunos teólogos; sin embargo, son cosas distintas que exigen distinto tratamiento teórico y práctico. El confundir los dos planos puede llevar a una lectura desviada de lo más profundo que quiere salvaguardar la Instrucción.

Para todo esto ayudará mucho un diálogo sincero. En la Instrucción se alude a que algunos teoblogos de la liberación no aceptan un verdadero diálogo, debido a un presupuesto clasista $(X, 3)$. No es el caso general ni mucho menos, aunque a veces si se exige que ambas partes tengan en cuenta sus condicionamientos limitantes a la hora de entender sus respectivas producciones y expresiones. La respuesta hasta ahora conocida de los teólogos de la liberación ha sido de apertura al diálogo y al discernimiento. También de parte de Roma se aprecia un esfuerzo de escuchar personalmente a los indiciados, que no han salido descontentos de la forma en que han sido recibidos.

La Instrucción, en definitiva, puede constituir un serio aporte pastoral para que llegue a consolidarse una auténtica teologla de la liberación. Para ello hace falta que se aproveche su vitalidad y las razones de esa vitalidad, que si la doctrina puede dar vida es, sobre todo, la vida creyente iluminada la que puede constituirse en sana y solida doctrina vivificante.

Juan Pablo Il en su breve visita a Santo Domingo con motivo de la preparación del quinto centenario del descubrimiento de América no se olvido del problema que aquí nos ocupa. Citó expresamente la Instrucción para que se tenga en cuenta tanto en la práctica pastoral como en la reflexión teológica. Pero lo enfocó positivamente. Ante todo, resaltó una vez más lo que es esencial a la teología de la liberación, la opción preferencial por los pobres, no sólo 
en la orientación de las actitudes éticas y religiosas, sino también en las estrictamente teológicas; este punto esencial, que ya va convirtiéndose explícitamente en un planteamiento central de la Iglesia universal, ha sido uno de los logros fundamentales de la le de las comunidades de base y de la reflexión teológica que las acompaña. El Papa, en segundo lugar, no se asusta de hablar explicitamente de la "liberación social" como forma de poner en práctica esa opción aunque en una línea de fidelidad al Evangelio, "que prohíbe el recurso a métodos de odio y de violencia." 37 También advierte que la opción preferencial no es exclusiva ni excluyente, que los pobres no han de entenderse como clase en lucha o como lglesia separada de los Pastores, que la liberación ha de tener en cuenta la vocación tanto terrena como eterna del hombre, que ha de evitar caer en sistemas que privan de la libertad, o en programas de ateísmo o de materialismo práctico, que ha de procurar la liberación del pecado interior y del mal moral que son causa del pecado social y de las estructuras opresoras.

Todo ello es sumamente positivo y orientador tanto para la pastoral de la Iglesia en su concreta situación latinoamericana caracterizada por la falta de justicia y de libertad como para la reflexión teológica. Será difícil hacerla ya en América Latina sin tener presente la perspectiva fundamental de la liberación integral. Si los considerados ordinariamente como teólogos de la liberación deberán tener cuidado en no caer en los defectos apuntados en la Insirucción y es de esperar que asi lo hagan con mayor esmero en los proximos escritos, los considerados sus opositores o simplemente los que descuidaban esta dimensión deberán sentirse fuertemente interpelados para cambiar su modo fundamental de hacer teología. Si ambas cosas se lograran, la Instrucción habría servido muchísimo para el bien de la Iglesia y desde luego para el bien de aquellas mayorias populares por las que se dice tener una opción preferencial.

\section{NOTAS}

1. Sagrada Congregación para la Docirina de la Fe, "Instrucción sobre algunos aspectos de la 'tcologia de la liberación,' "' L'Osservalore Romano, ed. en español, 9 de septiembre de 1984, $7-10$.

2. Comisión Teológica Internacional, "Promoción humana y salvación cristiana" en Teologia de la liberación, Madrid 1978, 183-210.

3. Ratzinger, J., "Vi spiego la teologia della liberazione," 30 Giorni, 3 de marzo de 1984, 4855 .

4. Codigo de Derecho Candnico, canon 360 .

5. Canon 34 .

6. Ver edición de la BAC, bajo la dirección de Lamberto de Echeverria, Madrid 1983.

7. Quarracino, A. "Algunos aspectos de la 'teología de la liberacion.' Lineas docirinales y pastorales del documento." L'Osservatore Romano, 1. c., 11.

8. Ib.

9. "Resumen del documento." L'Osservalore Romano, 1. c. II.

10. Quarracino, A. 1. c.

I1. Ver Nota 3.

12. 1 b. 48 .

13. Ib. 55.

14. Puebla. La evangelización en el presente y en el futuro de America Latina. San Salvador, 1979, 30. 
15. J. Ratzinger, Enifuhrung in des Christentum, München, 1968.

16. I. c. Il, I.

17. I. c. I1, 3 .

18. 1. c. II, 2.

19. I. Ellacuria, "Historicidad de la salvación cristiana," Revisla Latinoamericana de Teolugia, 1984, I, 5-45. Ver J.W. Hill "The historicity of God," Theological Siudies, junio de 1984, 320-333.

20. Summa Theologica, II-II, q. 66, a. 7.

21. Ver "La desmitilicación del marxismo," ECA, 1983, 421-422, 921-930.

22. Ocrogessima adveniens, No. 34.

23. Pacem in terris, No. 159.

24. Carta de Marx a Weydemeyer, 5 de marzo de 1852.

25. 1. c., I, a.

26. Ver nota 9.

27. Ver DIAL, D 149, 23-30, marzo de 1984, 1-2.

28. Carta de la Sagrada Congregación para la Doctrina de la Fe al R. P. Leonardo Boff, OFM, Prot. n. 2012/67, 15 de mayo de 1984.

29. Ver nota 3.

30. G. Gutièrrez, Beber de su propio pozo, Lima, 1983.

31. G. Gutiérrez, "Teologia y ciencias sociales," Páginas, septiembre de 1984, pp. 4-15.

32. Ib., 12.

33. J. Alfaro, "Análisis del libro 'Jesús en América Latina," Revista Latinoamericana de Teologia, 1984, I, 83-101.

Las páginas que el propio Sobrino escribe en este mismo numero tanto sobre espiritualidad como sobre la Instrucción sirven de prueba adicional y actualizada.

34. C. Boff, Teologia de la polftica, sus mediaciones. Salamanca, 1980, 123.

35. Jb., 124.

36. Ver en este mismo número de la revista algunas declaraciones de los mas connotados. Asimismo puede consultarse el número especial dedicado a la teologia de la liberación por Mision A bierta 1984, 4. El articulo de Jose L. Idigoras "Teologia latinoamericana ¿Teologla de la liberacion?"' recogido en Men.saje Iberoomericano, mayo de 1984, es interesante en su ponderación por venir de alguien que es crítico de la leología de la liberación. Asimismo es interesante el breve comentario de A. Dulles, "Liberalion Theology: Contrasting Types," América, 22 de septiembre de 1984, 138-139, en el cual por un lado dice que cierta retórica de la Instrucción puede fomentar el odio de clases, pero por otro ve positivo e importante para la lglesia que se trabaje por una teologia de la liberación.

37. Homilia de Juan Pablo IJ, II de octubre, L'Osservatore Romano, edicion semanal en lengua espahola, 21 de octubre de 1984, pp. 8-9. 